\title{
Panel cointegration tests of the Fisher effect
}

\author{
Citation for published version (APA):
}

Westerlund, J. (2006). Panel cointegration tests of the Fisher effect. METEOR, Maastricht University School of Business and Economics. METEOR Research Memorandum No. 054 https://doi.org/10.26481/umamet.2006054

Document status and date:

Published: 01/01/2006

DOI:

10.26481/umamet.2006054

Document Version:

Publisher's PDF, also known as Version of record

\section{Please check the document version of this publication:}

- A submitted manuscript is the version of the article upon submission and before peer-review. There can be important differences between the submitted version and the official published version of record.

People interested in the research are advised to contact the author for the final version of the publication, or visit the DOI to the publisher's website.

- The final author version and the galley proof are versions of the publication after peer review.

- The final published version features the final layout of the paper including the volume, issue and page numbers.

Link to publication

\footnotetext{
General rights rights.

- You may freely distribute the URL identifying the publication in the public portal. please follow below link for the End User Agreement:

www.umlib.nl/taverne-license

Take down policy

If you believe that this document breaches copyright please contact us at:

repository@maastrichtuniversity.nl

providing details and we will investigate your claim.
}

Copyright and moral rights for the publications made accessible in the public portal are retained by the authors and/or other copyright owners and it is a condition of accessing publications that users recognise and abide by the legal requirements associated with these

- Users may download and print one copy of any publication from the public portal for the purpose of private study or research.

- You may not further distribute the material or use it for any profit-making activity or commercial gain

If the publication is distributed under the terms of Article $25 \mathrm{fa}$ of the Dutch Copyright Act, indicated by the "Taverne" license above, 
Joakim Westerlund

Panel Cointegration Tests of the Fisher Effect

RM/06/054

JEL code : C12, C22, C23, E40

\section{METEबrR}

Maastricht research school of Economics

of TEchnology and ORganizations

Universiteit Maastricht

Faculty of Economics and Business Administration P.O. Box 616

NL - 6200 MD Maastricht

phone : ++31 433883830

fax : ++31433884873 



\title{
Panel Cointegration Tests of the Fisher Effect*
}

\author{
Joakim Westerlund ${ }^{\dagger}$
}

November 20, 2006

\begin{abstract}
Most empirical evidence suggest that the Fisher effect, stating that inflation and nominal interest rates should cointegrate with a unit slope on inflation, does not hold, a finding at odds with many theoretical models. This paper argues that these results can be attributed in part to the low power of univariate tests, and that the use of panel data can generate more powerful tests. For this purpose, we propose two new panel cointegration tests that can be applied under very general conditions, and that are shown by simulation to be more powerful than other existing tests. These tests are applied to a panel of quarterly data covering 20 OECD countries between 1980 and 2004. The evidence suggest that the Fisher effect cannot be rejected once the panel evidence on cointegration has been taken into account.
\end{abstract}

JEL Classification: C12; C22; C23; E40.

Keywords: Fisher Effect; Panel Cointegration Test; Cross-Sectional Dependence.

\section{Introduction}

The extent to which movements in nominal interest rates reflect movements in the expected rate of inflation has been one of the most researched areas in economics ever since Fisher (1930) first theorized that, over the long term,

\footnotetext{
* Earlier versions of this paper were presented at seminars at Lund University and Uppsala University. The author would like to thank seminar participants, Anindya Banerjee, Syed Basher, David Edgerton, Robert King, Rolf Larsson, Johan Lyhagen, Jean-Pierre Urbain, and in particular Hashem Pesaran and three anonymous for their very constructive comments, which led to a much improved presentation. The author would also like to thank the Maastricht Research School of Economics of Technology and Organizations for its hospitality during a visit at the Depertment of Quantitative Economics at the University of Maastricht, where a part of this paper was written. Thank you also to the Jan Wallander and Tom Hedelius Foundation for financial support under research grant number W2006-0068:1. The usual disclaimer applies.

${ }^{\dagger}$ Department of Economics, Lund University, P. O. Box 7082, S-220 07 Lund, Sweden. Telephone: +46 46222 4970; Fax: +46 46222 4118; E-mail address: joakim.westerlund@nek.lu.se.
} 
efficient capital markets should compensate for changes in the purchasing power of money. In its strictest form with no taxes and rational expectations, this theory, known as the Fisher effect, posits the existence of a constant real rate of interest, being determined largely by the time preference of economic agents and by the technological constraints that define the return on real investment. These factors are believed to be roughly constant over time, and therefore a fully perceived change in the purchasing power of money, as measured by the inverse of the rate of inflation, should be accompanied by a one-for-one change in the nominal interest rate.

Despite the wide acceptance of the Fisher effect in theory, the postulated long-run one-for-one relationship between inflation and nominal interest rates has proven very difficult to verify empirically, in spite of the recent advances in econometric methodology for testing long-run relationships using cointegration techniques. In fact, most studies tend to reject the Fisher effect as a long-run cointegrating relationship, see for example Rose (1988), MacDonald and Murphy (1989), Bonham (1991), and King and Watson (1997). Other studies, including Mishkin (1992), Crowder and Hoffman (1992), and Evans and Lewis (1995), do not reject cointegration, but with an estimated slope on inflation significantly different from one.

Findings of this sort are very puzzling since they imply that the ex ante real interest rate should be nonstationary. As pointed out by Rose (1988), this is inconsistent with standard consumption based asset pricing models insofar these predict that consumption growth rates should also be nonstationary, a hypothesis typically rejected by the data. Furthermore, assuming that inflation is primarily driven be monetary growth, superneutrality fails since changes in the rate of monetary growth affect inflationary expectations and subsequently real rates.

Most attempts to reconcile these contradictory results have taken the empirical evidence more or less at face value and have then modified the theoretical arguments. For example, Mundell (1963) and Tobin (1965) argue that inflation and nominal interest rates may be negatively correlated, and that this can be one explanation for why the estimated slope is sometimes less than one. Similarly, Darby (1975) points out that the presence of taxes can explain for why the estimated slope is sometimes larger than one. A popular argument for why cointegration has been so hard to establish is that replacing expected with actual inflation may cause serial correlation patterns in the residuals that are akin to those of a random walk, see Evans and Lewis (1995).

In this paper, we will take the alternative route and focus instead on the econometric cointegration based methodology used for testing the Fisher effect. We argue that the existing empirical evidence concerning the Fisher effect is flawed in at least two respects, and that this may well at least partially explain the contradictory results previously obtained. It therefore seems reasonable to investigate these problems before embarking on further revisions of economic 
theory.

One problem is that most studies employ methods that are designed to test the null hypothesis of no cointegration, and these are known to suffer from low power when the equilibrium errors are highly persistent under the alternative of cointegration. Thus, low power in the tests could be one explanation for why cointegration has been so difficult to find.

Another related problem is that most, if not all, studies have employed relatively small data sets, typically no more than 50 annual observations for a single country. Moreover, a majority of studies have been concerned with United States, and only a few attempts have been made to test the Fisher effect internationally. Besides leading to tests with low power, this makes crosscountry comparisons difficult.

Two examples of studies that have looked at more than one country are Ghazali and Ramlee (2003) and Koustas and Serletis (1999). Ghazali and Ramlee (2003) employ monthly data from January 1974 to June 1996 on the G7 countries, and cannot reject the null hypothesis of no cointegration between the nominal interest rate and inflation. Similarly, using quarterly data covering roughly the period 1957 to 1995 for 11 OECD countries, Koustas and Serletis (1999) find no evidence of cointegration for any of the countries except Japan. Both studies therefore reject the Fisher effect, which is indicative of its poor support internationally.

The problem with these two studies is that they use a country-by-country approach, in which conventional cointegration tests are applied to each country separately. Although this certainly makes the results comparable across countries, it does not really bring any more information into the analysis, since the information contained in the cross-sectional dimension is essentially disregarded. What is needed here is a testing approach that takes full account of the panel structure of the data. Such a strategy is likely to be more powerful, and thus more successful in detecting deviations from the no cointegration null.

In this paper, we make an attempt in this direction by proposing a panel testing approach, drawing upon a panel of 20 OECD countries between the first quarter of 1980 and the fourth quarter of 2004. In so doing, we pay special attention to the many features that characterize this type of macroeconomic data. For example, given the high degree of integration that exist within the OECD community, dependence across countries is likely to be the rule rather than the exception. Another important feature that needs to be addressed is that inflation may not be strictly nonstationary, and the testing procedure must thus permit the regressors to be stationary, see Ng and Perron (1997).

Unfortunately, these considerations invalidate the use of most existing panel cointegration tests, which rely critically on the assumptions of nonstationary regressors and independence between the cross-sectional units. We therefore develop two new panel cointegration tests of the null hypothesis of no cointegration that can be applied under very general conditions. These tests are 
based on the Durbin-Hausman principle, whereby two estimators of a unit root in the residuals of an estimated regression are compared. To correct for factors that are common across units, the new tests are based on defactored residuals. The asymptotic distributions of the tests are derived and shown to be normal. Results from a small Monte Carlo study suggest that the tests have small size distortions and greater power than other popular panel cointegration tests.

In the empirical part of the paper, we show that a failure to reject the null of no cointegration for an individual country need not be taken as firm evidence against the Fisher effect, and that the use of panel data produces more accurate results. We do this by first showing that the null of no cointegration cannot be rejected at conventional significance levels when using data on individual countries, and that this can in part be attributed to the low power of the methodology being used. We then show that the same null can be safely rejected when using our panel data tests. We also provide evidence to suggest that the hypothesis of a unit slope on inflation cannot be rejected for any of the countries nor for the panel as a whole.

The paper proceeds as follows. Section 2 provides a brief presentation of the Fisher effect. Section 3 introduces the Durbin-Hausman tests, while Section 4 is concerned with their empirical implementation in testing the Fisher effect. Section 5 concludes.

\section{The Fisher effect}

In this section, we begin with a brief account of the economic theory underlying the Fisher effect, and then we go on to discuss the empirical methods that has been used to test it.

\subsection{Theoretical underpinnings}

The Fisher effect states that, over the longer term, real interest rates across countries should be approximately constant with movements in nominal interest rates reflecting movements in the rate of inflation in a one-for-one manner. Formally, the Fisher identity can be stated as

$$
i_{i t}=\pi_{i t}+r_{i t}
$$

where $\pi_{i t}$ is the actual rate of inflation observed at time period $t$ for country $i, i_{i t}$ is the ex post nominal interest rate on a nominal bond and $r_{i t}$ is the corresponding ex ante real interest rate. ${ }^{1}$ Note that this identity implicitly assumes that the tax rate on nominal returns is zero. We will discuss the

\footnotetext{
${ }^{1}$ Equation (1) is sometimes made more specific by indexing the variables by the time period of the bond to maturity. Since the Fisher theory applies to all maturities, however, we do not bother with this distinction.
} 
impact of a nonzero tax rate later. By taking expectations conditional on all information available at time $t$, equation (1) becomes

$$
E_{t}\left(i_{i t}\right)=E_{t}\left(\pi_{i t}\right)+E_{t}\left(r_{i t}\right) .
$$

For bonds that are held to maturity, the nominal rate of interest is contracted in advance, suggesting that (2) can be written as

$$
i_{i t}=E_{t}\left(\pi_{i t}\right)+E_{t}\left(r_{i t}\right) .
$$

Combining (1) and (3) yields

$$
r_{i t}-E_{t}\left(r_{i t}\right)=-\left(\pi_{i t}-E_{t}\left(\pi_{i t}\right)\right) .
$$

Thus, according to this theory, unanticipated movements in the real interest rate reflect unanticipated movements in inflation one-for-one.

Moreover, if expectations are formed rationally, then

$$
\pi_{i t}=E_{t}\left(\pi_{i t}\right)+\varepsilon_{i t},
$$

where $\varepsilon_{i t}$ is a mean zero stationary forecast error that is orthogonal to any information known at time $t$. By inserting this equation into (3), it is seen that the following relationship must hold

$$
i_{i t}-\pi_{i t}=E_{t}\left(r_{i t}\right)-\varepsilon_{i t} .
$$

Since both $i_{i t}$ and $\pi_{i t}$ are observable, this equation provides a natural basis for an empirical framework, in which the Fisher effect can be tested. In fact, it is readily seen that the following regression can be used

$$
i_{i t}=\alpha_{i}+\beta_{i} \pi_{i t}+z_{i t} .
$$

In this regression, $z_{i t}$ can be thought of as a composite error term, comprised of an unexplained regression error plus another term $-\beta_{i} \varepsilon_{i t}$, which is the error from using $\pi_{i t}$ instead of $E_{t}\left(\pi_{i t}\right)$ as regressor. Furthermore, it is convenient to think of the intercept $\alpha_{i}$ as representing the mean of the ex ante real interest rate, which is typically assumed to be constant over time, see MacDonald and Murphy (1989). This seems reasonable given that the ex ante rate should not change much if the Fisher effect it true. The parameter of greatest interest, however, is $\beta_{i}$, which measures the extent to which the Fisher effect can be regarded as true. Under the conditions laid out in the above, the Fisher effect implies that $\beta_{i}$ should be equal to one.

The paradox of the Fisher effect is that, despite its wide acceptance in theory, most empirical evidence seem to be inconsistent with the hypothesized one-forone relationship between inflation and nominal interest rates. This anomaly was noted by Fisher (1930) himself, who attributed it to some kind of money illusion, 
in which economic agents do not take full account of the effect of inflation on their nominal return.

Money illusion is one explanation for observing $\beta_{i}$ less than one. However, this would imply that economic agents are irrational. A more popular explanation for why $\beta_{i}$ may be less than one is provided by Mundell (1963) and Tobin (1965), who argue that inflation and nominal interest rates may be inversely related. The idea is that higher inflation may cause a substitution away from money balances towards bonds and real assets, which would then put downward pressure on the real interest rate, as the required return on bonds and marginal productivity of capital would tend to fall. Carmichael and Stebbing (1983) go even further and argue a perfect inverse relationship, sometimes known as the inverted Fisher effect.

Darby (1975), on the other hand, considers the case when nominal interest income is taxed, and argues that this may explain why $\beta_{i}$ can sometimes be larger than one. To see this, consider the following tax-adjusted Fisher equation

$$
i_{i t}=\left(\frac{1}{1-\tau_{i}}\right) \pi_{i t}+\left(\frac{1}{1-\tau_{i}}\right) E_{t}\left(r_{i t}\right)-\varepsilon_{i t}
$$

where $\tau_{i}$ is the average marginal tax rate on the nominal interest income of country $i$. Note that in this scenario, a $1 \%$ increase in $\pi_{i t}$ raises the pre-tax nominal rate by $1 /\left(1-\tau_{i}\right)$, so that the post-tax real rate of return given by $i_{i t}-\left(1-\tau_{i}\right) \pi_{i t}$ remain unaffected. If we compare the above equation with our regression model, we see that $\beta_{i}$ must be equal to $1 /\left(1-\tau_{i}\right)$ if the Fisher effect holds. Thus, a positive tax rate can cause $\beta_{i}$ to become greater than one.

\subsection{Tests based on cointegration}

Fisher (1930) emphasized that the adjustment towards the hypothesized relationship between the nominal interest and inflation rates could potentially take very long time. Consistent with this view, there has been increasing recognition that the Fisher equation should be interpreted as a long-run relation, which, as pointed out by MacDonald and Murphy (1989), is best tested using cointegration analysis.

Consider therefore the regression in (5), and assume that $i_{i t}$ and $\pi_{i t}$ are nonstationary. This regression is cointegrated if $z_{i t}$ is stationary and it is spurious if $z_{i t}$ is nonstationary. The Fisher effect posits that changes in $E_{t}\left(\pi_{i t}\right)$ should be reflected fully in subsequent movements of $i_{i t}$ over time, which, in terms of our test regression, implies that the inflation and nominal interest rates should cointegrate with a unit slope on inflation. In keeping with the notational convention introduced by Owen (1993), we shall henceforth refer to this as the full Fisher effect. ${ }^{2}$

\footnotetext{
${ }^{2}$ Note that, although cointegration with a unit slope on inflation is typically referred to as the full Fisher effect, as alluded in the introduction, this is actually only a necessary condition
} 
Interestingly, as pointed out by Mishkin (1992), given rational expectations, testing the full Fisher effect is equivalent to testing the stationarity of the ex ante real interest rate. To see this, note that (4) and (5) can be rewritten as

$$
E_{t}\left(r_{i t}\right)=\alpha_{i}-\left(1-\beta_{i}\right) \pi_{i t}+z_{i t}+\varepsilon_{i t} .
$$

Suppose now that the inflation and nominal interest rates are cointegrated. In this case, $z_{i t}$ must be stationary, so the integratedness of the ex ante rate depends only on the integratedness of the term $\left(1-\beta_{i}\right) \pi_{i t}$, as the forecast error $\varepsilon_{i t}$ must be stationary under our assumption of rational expectations. If $\beta_{i}=1$, then $\left(1-\beta_{i}\right) \pi_{i t}$ vanishes so variations in the ex ante real rate reflect only temporary deviations from its mean value $\alpha_{i}$. Intuitively, since the nominal interest rate moves one-for-one with the rate of inflation in the long run, their unit root components cancel out leaving the ex ante real rate unaffected, in which case the full Fisher effect holds.

On the other hand, if $\beta_{i}$ is different from one, either larger than one as argued by Darby (1975) or less than one as argued by Mundell (1963) and Tobin (1965), then $\left(1-\beta_{i}\right) \pi_{i t}$ will not vanish, which suggests that the ex ante real interest rate must contain the same unit root component as inflation. Of course, the inflation and nominal interest rates may still be cointegrated even though the ex ante real rate is nonstationary. But since $\beta_{i}$ is not one, there is said to be only a partial Fisher effect (Owen, 1993). If inflation and nominal interest do not cointegrate, then $z_{i t}$ has a unit root and there can be no Fisher effect. It follows that cointegration is a necessary condition for the Fisher effect to hold in the long run.

The conventional way in which earlier studies have been trying to test the partial version of Fisher effect involves first estimating (5) by ordinary least squares (OLS) and then testing whether the residuals from that equation can be regarded as stationary or not by using any conventional cointegration test. ${ }^{3}$ This test is then repeated for every country in the sample, each time using only the sample information for that particular country. Studies based on this approach are generally unable to reject the null hypothesis of no cointegration, which is seen to imply that the Fisher effect should be rejected. In this paper, we argue that this result should not be taken at face value as a failure to reject the null can be due to low power.

for the Fisher effect to hold. Hence, the finding of cointegration with a unit slope is by itself not enough to conclude that the Fisher effect holds, as it is consistent with any theory that implies a stationary real rate. For the current paper, however, this is not a critical aspect, as we are mainly interested in examining whether low power could be one explanation for why the full Fisher effect is usually rejected.

${ }^{3}$ Since nominal interest rates and inflation are variables that are simultaneously determined within a wider economic system, some authors, most recently Garratt et al. (2003), have gone from analyzing the Fisher equation in isolation to a more general approach where the Fisher effect is analyzed as a part of a larger macroeconometric model. Our approach is more parsimonious and is robust against such simultaneity. 
In fact, it is well known that tests that take no cointegration as the null hypothesis can have very little power against nearly cointegrated alternatives. As pointed out by Evans and Lewis (1995), this critique is likely to be particularly important when testing the Fisher effect, as the forecast error of inflation can be highly persistent in because of anticipated process shifts. But if $\varepsilon_{i t}$ is nearly nonstationary then so is $z_{i t}$ suggesting that tests based on the residuals from (5) will tend to be biased towards accepting the no cointegration null. In addition to this, we have the classical mechanism of hypothesis testing, which guarantees that the null hypothesis will not be rejected unless there is very strong evidence against it.

In a situation like this, it is essential to device tests with increased power. A natural approach to this end would be to combine the sample information from the time series dimension with that from the cross-sectional. This not only increases the power by taking the total number of observations and their variation into account, but also increases the precision of the test by effectively reducing the noise coming from the individual time series regressions. Therefore, one way to augment the power of univariate tests would be to subject the residuals from (5) to a panel data cointegration test.

Unfortunately, most existing tests of this kind rely critically on assuming that the cross-sectional units are independent of each other, see Pedroni (2004) and Westerlund (2005) among others. ${ }^{4}$ As O'Connell (1998) has shown, when this assumption is violated, tests that are based upon it become invalid. In our case, there are at least two reasons for believing that the data may not be independent cross-sectionally. First, inflation rates may be correlated across countries because of common oil price shocks. Second, interest rates may be correlated across countries due to strong intra-economy linkages in the financial markets.

A theoretically very appealing interpretation of this latter dependence is that it reflects in part the presence of a world real interest rate, see Lee (2002). To illustrate this, consider the following decomposition of the ex ante real rate

$$
E_{t}\left(r_{i t}\right)=\lambda_{i} r_{t}+e_{i t}
$$

where $r_{t}$ is the world rate, $\lambda_{i}$ is the loading associated with $r_{t}$ and $e_{i t}$ is an idiosyncratic disturbance reflecting country specific variations. Note that since $r_{t}$ is common for all countries, this makes the ex ante real rate cross-sectionally correlated, which in turn induces a similar dependence in the ex post rate.

Another problem with existing tests for cointegration in panel data is that they assume that both the inflation and nominal interest rates are strictly nonstationary, and their asymptotic properties become suspect when this condition

\footnotetext{
${ }^{4}$ It has become common practice to use data that has been demeaned with respect to a common time effect, which permits for some cross-sectional dependence. Unfortunately, this approach is not enough to get rid of the dependence in general when the pair-wise crosssectional correlations are permitted to differ.
} 
is not satisfied. This issue has been analyzed to some extent by Ng and Perron (1997), who argue that cointegration tests of the Fisher effect are likely to be biased in sofar inflation can be expected to be only weakly nonstationary.

This discussion suggests that a first crucial step in testing the Fisher effect using panel data is to construct tests that allow the cross-sectional units to be correlated, and that do not rely to such a large extent on a priori knowledge regarding the integratedness of the variables.

\section{The Durbin-Hausman tests}

The previous section suggests that testing for cointegration in cross-sectionally dependent data with weak unit roots is key in inferring the Fisher effect. This section therefore proposes two new panel cointegration tests that allow for such features, and that are shown by simulation to be more powerful than other panel data tests.

\subsection{Model and assumptions}

We begin by assuming that the Fisher equation (5) holds so that

$$
\begin{aligned}
i_{i t} & =\alpha_{i}+\beta_{i} \pi_{i t}+z_{i t} . \\
\pi_{i t} & =\delta_{i} \pi_{i t-1}+w_{i t},
\end{aligned}
$$

We have argued above that, although the nominal interest rate can in general be viewed as nonstationary, it seems reasonable to permit inflation to be stationary. In this section, therefore, we do not impose any a priori restrictions on the value taken by $\delta_{i}$. If $\delta_{i}=1$, then inflation is nonstationary, whereas if $\delta_{i}<1$, inflation is stationary.

The disturbance $z_{i t}$ is assumed to obey the following set of equations that permit for cross-sectional dependence through the use of common factors

$$
\begin{aligned}
z_{i t} & =\lambda_{i}^{\prime} F_{t}+e_{i t}, \\
F_{j t} & =\rho_{j} F_{j t-1}+u_{j t}, \\
e_{i t} & =\phi_{i} e_{i t-1}+v_{i t},
\end{aligned}
$$

where $F_{t}$ is a $k$ dimensional vector of common factors $F_{j t}$ with $j=1, \ldots, k$, and $\lambda_{i}$ is a conformable vector of factor loadings. By assuming that $\rho_{j}<$ 1 for all $j$, we ensure that $F_{t}$ is strictly stationary, which implies that the order of integration of the composite regression error $z_{i t}$ depend only on the integratedness of the idiosyncratic disturbance $e_{i t}$. Thus, in this data generating process, the relationship in (7) is cointegrated if $\phi_{i}<1$ and it is spurious if $\phi_{i}=1$. Note that, since $i_{i t}$ is assumed to be nonstationary, $\phi_{i}<1$ implies both that $\pi_{i t}$ is nonstationary and that it is cointegrated with $i_{i t}$, see Section 3.3 for a more thorough discussion. 
Next, we lay out the key assumptions needed for developing the new tests.

Assumption 1. (Error process.)

(a) $v_{i t}$ and $w_{i t}$ are mean zero for all $i$ and $t$;

(b) $E\left(v_{i t} v_{k j}\right)=0$ and $E\left(w_{i t} w_{k j}\right)=0$ for all $i \neq k, t$ and $j$;

(c) $E\left(v_{i t} w_{k j}\right)=0$ for all $i, k, t$ and $j$;

(d) $\operatorname{var}\left(v_{i t}\right)=\omega_{i}^{2}<\infty$ and $\operatorname{var}\left(w_{i t}\right)=\Omega_{i}$ is positive definite.

For the asymptotic theory, the following condition is also required.

Assumption 2. (Invariance principle.) The partial sum processes of $v_{i t}$ and $w_{i t}$ satisfy an invariance principle. In particular, $T^{-1 / 2} \sum_{t=1}^{[r T]} v_{i t} \Rightarrow \omega_{i} W_{i}(r)$ as $T \rightarrow \infty$ for each $i$, where $\Rightarrow$ denotes weak convergence and $W_{i}(r)$ is a standard Brownian motion defined on the unit interval $r \in[0,1]$.

Finally, to be able to handle the common factors, the following conditions are assumed to hold.

Assumption 3. (Common factors.)

(a) $E\left(u_{t}\right)=0$ and $\operatorname{var}\left(u_{t}\right)<\infty$;

(b) $u_{t}$ is independent of $v_{i t}$ and $w_{i t}$ for all $i$ and $t$;

(c) $\frac{1}{N} \sum_{i=1}^{N} \lambda_{i} \lambda_{i}^{\prime} \rightarrow \Sigma$ as $N \rightarrow \infty$, where $\Sigma$ is positive definite;

(d) $\rho_{j}<1$ for all $j$.

Assumptions 1 (a) and (b) state that $v_{i t}$ and $w_{i t}$ are mean zero processes, and that they are cross-sectionally independent, which implies that any dependence across units is restricted to the common factors. The extent of this dependence is determined by $\lambda_{i}$, as can be seen by writing $E\left(z_{i t} z_{j t}\right)=\lambda_{i}^{\prime} E\left(F_{t} F_{t}^{\prime}\right) \lambda_{j}$ for all $i \neq j$. Thus, the factors make the units correlated through $z_{i t}$. In terms of the discussion of the previous section, it is convenient to think of $F_{t}$ as comprised of the world real interest rate and possibly also other factors that are common across the members of the panel.

Assumption 1 (c) states that $v_{i t}$ and $w_{i t}$ are independent as groups, which is satisfied if the regressor is strictly exogenous. Although somewhat restrictive, this assumption can be readily relaxed to accommodate non-strict exogeneity by conditioning (7) on the lags and leads of $w_{i t}$. Assumption 1 (d) states that $\Omega_{i}$ is positive definite, which means that $\pi_{i t}$ cannot be cointegrated in case we have multiple regressors. Although not strictly necessary, as argued in Section 3.3 , in this paper we retain this condition to simplify the interpretation of the test outcome.

Assumption 2 states that an invariance principle applies to the partial sum processes constructed from $v_{i t}$ and $w_{i t}$ as $T$ grows for a given $i$. Apart from 
some mild regulatory conditions on the existence of higher order moments, this assumption places little restriction on the temporal dependencies of $v_{i t}$ and $w_{i t}$, and encompasses for example the broad class of all stationary autoregressive moving average models. ${ }^{5}$ It also allows the asymptotic covariance structure absorbed in $\omega_{i}^{2}$ and $\Omega_{i}$ to differ between the cross-sectional units.

Assumptions 3 (a) and (b) ensure the consistency of the principal components estimates of the common factors. They also ensure that an invariance principle holds for the partial sum process of $u_{t}$, and that this disturbance is independent of the idiosyncratic one. These assumptions are standard in common factor analysis. Assumption 1 (c) ensures that the common factors have a nontrivial contribution to the variation of $z_{i t}$, which in turn ensures that the factor model is identified.

Finally, although the Assumption 3 (d) requires the factors to be stationary, recent results by Bai and $\mathrm{Ng}$ (2004) indicate that this might not be strictly necessary. Specifically, in order to allow for deviations from Assumption 3 (d), Bai and Ng (2004) propose using a unit root pretesting scheme to determine the integratedness of the common component. In the current context, if some of the factors are found to be nonstationary, then one concludes that the spuriousness of (7) is due to the common component, and proceed no further. However, if the factors are found to be stationary, as assumed here, then one may proceed exactly as will be described later in this section, by testing the idiosyncratic component for a unit root. The asymptotic justification for using this procedure follows from the consistency of the estimated factors, as shown in the appendix.

\subsection{Test construction}

Our objective is to test whether $i_{i t}$ and $\pi_{i t}$ are cointegrated or not by inferring whether $e_{i t}$ is stationary or not. A natural approach to do this is to employ the Bai and Ng (2004) approach, which amounts to first estimating (7) in its first difference form by OLS and then to estimate the common factors by applying the method of principal components to the resulting residuals. A test of the null hypothesis of no cointegration can then be implemented as a unit root test of the recumulated sum of the defactored and first differentiated residuals. ${ }^{6}$

We begin by taking first differences, in which case (9) becomes

$$
\Delta z_{i t}=\lambda_{i}^{\prime} \Delta F_{t}+\Delta e_{i t} .
$$

Thus, had $\Delta z_{i t}$ been known, we could have estimated $\lambda_{i}$ and $\Delta F_{t}$ directly by the method of principal components. However, $\Delta z_{i t}$ is not known, and we must therefore apply principal components to its OLS estimate instead, which can be

\footnotetext{
${ }^{5}$ See Bai and $\mathrm{Ng}$ (2004) for a more thorough discussion regarding the technical moment conditions required.

${ }^{6}$ See Banerjee and Carrion-i-Silvestre (2006) and Gengenbach et al. (2006) for a similar approaches.
} 
written as

$$
\Delta \widehat{z}_{i t}=\Delta i_{i t}-\widehat{\beta}_{i} \Delta \pi_{i t}
$$

where $\widehat{\beta}_{i}$ is obtained by regressing $\Delta i_{i t}$ on $\Delta \pi_{i t}$. Let $\lambda, \Delta F$ and $\Delta \widehat{z}$ be $K \times N$, $(T-1) \times K$ and $(T-1) \times N$ matrices of stacked observations on $\lambda_{i}, \Delta F_{t}$ and $\Delta \widehat{z}_{i t}$, respectively. The principal components estimator $\Delta \widehat{F}$ of $\Delta F$ can be obtained by computing $\sqrt{T-1}$ times the eigenvectors corresponding to the $K$ largest eigenvalues of the $(T-1) \times(T-1)$ matrix $\Delta \widehat{z} \Delta \widehat{z}^{\prime}$. The corresponding matrix of estimated factor loadings is given by $\widehat{\lambda}=\Delta \widehat{F}^{\prime} \Delta \widehat{z} /(T-1)$. Given $\widehat{\lambda}_{i}$ and $\Delta \widehat{F}_{t}$, the defactored and first differentiated residuals can be recovered as

$$
\Delta \widehat{e}_{i t}=\Delta \widehat{z}_{i t}-\widehat{\lambda}_{i}^{\prime} \Delta \widehat{F}_{t},
$$

which can be recumulated to obtain

$$
\widehat{e}_{i t}=\sum_{j=2}^{t} \Delta \widehat{e}_{i j}
$$

As shown in the appendix, $\widehat{e}_{i t}$ is a consistent estimate of $e_{i t}$, which suggests that the cointegration test can be implemented using (11) with $\widehat{e}_{i t}$ in place of $e_{i t}$. In other words, testing the null hypothesis of no cointegration is asymptotically equivalent to testing whether $\phi_{i}=1$ in the following autoregression

$$
\widehat{e}_{i t}=\phi_{i} \widehat{e}_{i t-1}+\text { error. }
$$

In what follows, we shall propose two new panel cointegration tests that are based on applying the Durbin-Hausman principle to (13), see Choi (1994). The first, the panel test, is constructed under the maintained assumption that $\phi_{i}=\phi$ for all $i$, while the second, the group mean test, is not. Both tests are composed of two estimators of $\phi_{i}$ that have different probability limits under the alternative hypothesis of cointegration but share the property of consistency under the null of no cointegration. In particular, let $\widehat{\phi}_{i}$ denote the OLS estimator of $\phi_{i}$ in (13), and let $\widehat{\phi}$ denote its pooled counterpart. The corresponding individual and pooled instrumental variables (IV) estimators of $\phi_{i}$, denoted $\widetilde{\phi}_{i}$ and $\widetilde{\phi}$, respectively, are obtained by simply instrumenting $\widehat{e}_{i t-1}$ with $\widehat{e}_{i t}$.

As shown by Choi (1994), the IV estimators are consistent under the null hypothesis but are inconsistent under the alternative. On the other hand, the OLS estimators are consistent both under the null and alternative hypotheses, see Phillips and Ouliaris (1990). The IV and OLS estimators can thus be used to construct the Durbin-Hausman tests.

In so doing, consider the following kernel estimator

$$
\widehat{\omega}_{i}^{2}=\frac{1}{T-1} \sum_{j=-M_{i}}^{M_{i}}\left(1-\frac{j}{M_{i}+1}\right) \sum_{t=j+1}^{T} \widehat{v}_{i t} \widehat{v}_{i t-j},
$$


where $\widehat{v}_{i t}$ is the OLS residual obtained from (13) and $M_{i}$ is a bandwidth parameter that determines how many autocovariances of $\widehat{v}_{i t}$ to estimate in the kernel. ${ }^{7}$ As indicated in the appendix, the quantity $\widehat{\omega}_{i}^{2}$ is a consistent estimate of $\omega_{i}^{2}$, the long-run variance of $v_{i t}$. The corresponding contemporaneous variance estimate is denoted by $\widehat{\sigma}_{i}^{2}$. Given these estimates, we can construct the two variance $\operatorname{ratios} \widehat{S}_{i}=\widehat{\omega}_{i}^{2} / \widehat{\sigma}_{i}^{4}$ and $\widehat{S}_{N}=\widehat{\omega}_{N}^{2} /\left(\widehat{\sigma}_{N}^{2}\right)^{2}$, where

$$
\widehat{\omega}_{N}^{2}=\frac{1}{N} \sum_{i=1}^{N} \widehat{\omega}_{i}^{2} \text { and } \widehat{\sigma}_{N}^{2}=\frac{1}{N} \sum_{i=1}^{N} \widehat{\sigma}_{i}^{2} .
$$

The Durbin-Hausman test statistics can now be obtained as

$$
D H_{g}=\sum_{i=1}^{N} \widehat{S}_{i}\left(\widetilde{\phi}_{i}-\widehat{\phi}_{i}\right)^{2} \sum_{t=2}^{T} \widehat{e}_{i t-1}^{2} \text { and } D H_{p}=\widehat{S}_{N}(\widetilde{\phi}-\widehat{\phi})^{2} \sum_{i=1}^{N} \sum_{t=2}^{T} \widehat{e}_{i t-1}^{2} \text {. }
$$

Note that while the panel statistic, denoted $D H_{p}$, is constructed by summing the $N$ individual terms before multiplying them together, the group mean statistic, denoted $D H_{g}$, is constructed by first multiplying the various terms and then summing. The importance of this distinction lies in the formulation of the alternative hypothesis. For the panel test, the null and alternative hypotheses is formulated as $H_{0}: \phi_{i}=1$ for all $i$ versus $H_{1}^{p}: \phi_{i}=\phi$ and $\phi<1$ for all $i$. Hence, in this case, we are in effect presuming a common value for the autoregressive parameter both under the null and alternative hypotheses. Thus, if this assumption holds, a rejection of the null should be taken as evidence in favor of cointegration for the entire panel. ${ }^{8}$

By contrast, for the group mean test, $H_{0}$ is tested versus the alternative that $H_{1}: \phi_{i}<1$ for at least some $i$. Thus, in this case, we are not presuming a common value for the autoregressive parameter and, as a consequence, a rejection of the null cannot be taken to suggest that the entire panel is cointegrated. Instead, a rejection should be interpreted as providing evidence in favor of rejecting the null hypothesis for at least some of the cross-sectional units.

Note also that both tests employ a multiplicative correction to account for the effects of serial correlation. This makes them computationally convenient in comparison to the popular residual-based tests of Pedroni (2004), in which the corrections enter both multiplicatively and additively. Also, in view of the panel test, note that, although the autoregressive parameters are presumed equal, both the variances and the cointegration vectors themselves are allowed to vary between the individual cross-sections.

\footnotetext{
${ }^{7}$ For consistency of the tests, it is necessary that the bandwidth $M_{i}$ does not increase too fast relative to $T$. The rate $o(\sqrt{T})$ is sufficient, see Phillips and Ouliaris (1990).

${ }^{8}$ Researchers should be aware though that despite this difference in the way the alternative hypothesis is viewed, both tests have power against both types of the alternatives. Thus, when the null hypothesis is rejected, without testing the homogeneity of the autoregressive parameters, one can generally only conclude that at least some of the panel members are cointegrated, even when $D H_{p}$ is used and so the null is tested against $H_{1}^{p}$.
} 


\subsection{Asymptotic distribution}

Pooling the data is valid when the asymptotic distribution of the test does not contain any terms that are common across $i$. The problem is that if the data admit to a common factor structure, as assumed here, conventional tests, such as those of Pedroni (2004) and Westerlund (2005), which are based on the composite error term $z_{i t}$, will not satisfy this condition due to the presence of the common factors. By contrast, the Durbin-Hausman tests are based on the estimated idiosyncratic error term $\widehat{e}_{i t}$, and are therefore asymptotically independent of these factors.

In particular, as shown in the appendix, under the null and Assumptions 1 through 3 , then each of the individual group mean statistics converges to

$$
B_{i}=\left(\int_{0}^{1} W_{i}(r)^{2} \mathrm{~d} r\right)^{-1} \text { as } N, T \rightarrow \infty .
$$

The fact that $B_{i}$ does not depend on the common factors is a direct consequence of the defactoring, which asymptotically removes the common component from the limiting distribution of the individual tests. Because of this, we can use standard central limit theory to obtain a limiting normal distribution for $\sqrt{N}$ times cross-sectional average of these tests. Let $C_{i}$ be the inverse of $B_{i}$. The following theorem shows that the effect of the common factors is asymptotically negligible, and that $D H_{g}$ and $D H_{p}$ are indeed asymptotically normal.

Theorem 1. (Asymptotic distributions.) Under the null hypothesis $H_{0}$ and Assumptions 1 through 3 , for $\delta_{i}=1$ or $\delta_{i}<1$, as $N, T \rightarrow \infty$ with $N / T \rightarrow 0$

$$
\begin{aligned}
N^{-1 / 2} D H_{g}-\sqrt{N} E\left(B_{i}\right) & \Rightarrow N\left(0, \operatorname{var}\left(B_{i}\right)\right), \\
N^{-1 / 2} D H_{p}-\sqrt{N} E\left(C_{i}\right)^{-1} & \Rightarrow N\left(0, E\left(C_{i}\right)^{-4} \operatorname{var}\left(C_{i}\right)\right) .
\end{aligned}
$$

Remark 1. The proof of Theorem 1 is outlined in the appendix but it is constructive to consider briefly why it holds. The proof begins by showing that

$$
T^{-1 / 2} \widehat{e}_{i t}=T^{-1 / 2} e_{i t}+o_{p}(1) .
$$

This suggests that a test based on $\widehat{e}_{i t}$ is asymptotically equivalent to a test based on $e_{i t}$. This is important for at least two reasons. First, since $e_{i t}$ does not depend on $\pi_{i t}$, the Durbin-Hausman tests have the unusual property that their limiting distributions are unaffected by the presence of the regressor. Second, since $e_{i t}$ is cross-sectionally independent, the distributions do not contain any elements that are common across $i$. Asymptotic normality of $D H_{g}$ and $D H_{p}$ therefore follows directly by conventional central limit theorem arguments.

Remark 2. The moments of the tests are obtained by simulation methods. That is, the elements of the Brownian motion functionals $B_{i}$ and $C_{i}$ are approximated by functions of sums of partial sums of $T$ independent draws from 
the standard normal distribution. Specifically, we generate 100,000 samples of length $T=1,000$, which are then used to obtain numerical values of the moments in Theorem 1. The simulated values of $E\left(B_{i}\right), \operatorname{var}\left(B_{i}\right), E\left(C_{i}\right)$ and $\operatorname{var}\left(C_{i}\right)$ using this method are 5.5464, 36.7673, 0.5005 and 0.3348 , respectively. Also, since each of the standardized statistics diverges to positive infinity under the alternative hypothesis, the computed value should be compared to the right tail of the normal distribution. If the computed value is greater than the appropriate right tail critical value, we reject the null hypothesis.

Remark 3. The fact that the asymptotic distributions of the tests are independent of the regressor is stronger than one might first realize. To take one example, there is only one set of critical values, even if we have multiple regressors, which is of course a great operational advantage. Moreover, because the estimation of $\beta_{i}$ is done using the first differences rather than the levels of the data, the only unit root in the system under the null is that of the errors obtained when recumulating $\Delta \widehat{e}_{i t}$. This stands in stark contrast to existing methods, which are based on estimating $\beta_{i}$ from (7) directly, and it is expected to produce more powerful tests. The reason for this is that having to estimate all unit roots in the system under the null leads to tests that are inefficient under the alternative of a single common unit root. Thus, the power of tests that depend on estimating $\beta_{i}$ from the level data is expected to decrease with the number of regressors in a way that the power of the new tests is not, see Westerlund and Edgerton (2006). ${ }^{9}$

Remark 4. Yet another advantage with the new tests is that they can be easily extended to incorporate a priori knowledge about $\beta_{i}$, which is particularly relevant in our application where the full Fisher effect postulates a unit slope on inflation. In fact, all one has to do is to replace $\Delta \widehat{z}_{i t}$, the estimated residual in (12), with its true value

$$
\Delta z_{i t}=\Delta i_{i t}-\beta_{i} \Delta \pi_{i t}
$$

The test can then be implemented exactly as described earlier. The advantage with doing the testing in this way is that it produces more powerful tests without affecting their asymptotic null distributions. The disadvantage is of course that the presumed cointegrating slope must be equal to the true slope. Otherwise the test will be unable to reject the no cointegration null even though there is cointegration but with a different slope. It is nevertheless interesting to note that there is generally no simple way to modify other cointegration tests to incorporate a priori information of this kind.

\footnotetext{
${ }^{9}$ Of course, since the new tests are based on estimating $\beta_{i}$ from (7) in first differences, the resulting OLS estimator is not an estimate of the cointegration vector under the alternative hypothesis, which could be argued to cause a reduction in power. However, this is incorrect as the asymptotic power of the tests is determined only by the speed of divergence of the estimate of $\phi_{i}$ in (13), which, as shown in the appendix, is unaltered.
} 
Remark 5. All results reported so far are based on the implicit assumption that $k$, the number of common factors, is known. When it is unknown, a natural approach is to treat the estimation problem as a model selection issue, and to estimate $k$ by minimizing an information criterion. The particular estimator opted for this paper is given as follows

$$
\widehat{k}=\underset{0 \leq k \leq k_{\max }}{\arg \min } \log \left(\widehat{\sigma}^{2}\right)+k \log \left(\frac{N T}{N+T}\right) \frac{N+T}{N T},
$$

where $\widehat{\sigma}^{2}=\frac{1}{N T} \sum_{i=1}^{N} \sum_{t=2}^{T}\left(\Delta \widehat{e}_{i t}\right)^{2}$ and $k_{\max }$ is an bounded integer not smaller than $k$. The use of this estimator is motivated in part by its popularity in studies such as Bai and Ng (2004), in part by its good performance in the simulations.

We have already pointed to several advantages with the new tests. There is, however, another very appealing feature that we have not mentioned yet, which is that the regressor need not be nonstationary. In fact, as pointed out earlier, the only requirement is that the dependent variable is nonstationary, which is tantamount to requiring that there is at least one unit root in the system. This condition is necessary to ensure the consistency of the tests, so that a rejection of the no cointegration null is not confused with a completely stationary regression. Similarly, the assumption of no regressor cointegration precludes the cases when there is cointegration under the null hypothesis, and when there is more than one cointegrating relationship under the alternative.

As pointed out by Cluver and Papell (1997), because there is considerable doubt concerning the integratedness of inflation, permitting the regressor to be stationary seems particularly relevant when testing the Fisher effect. Ng and Perron (1997) investigate this issue and find that the presence of nearly stationary regressors can have serious consequences for cointegration tests that are based on estimating $\beta_{i}$ from a level regression. By contrast, the new tests are based on estimating $\beta_{i}$ from a regression in first differences, and are therefore robust in this sense.

The fact that the regressor may be stationary suggest a very simple test procedure that does not involve any unit root pretesting, which is expected to reduce the overall uncertainty of the test. In this regard, the Durbin-Hausman tests are actually very similar to the bounds testing approach developed by Pesaran et al. (2001), which do not require any a priori knowledge about the integratedness of the data.

The procedure that we propose begins by applying the Durbin-Hausman tests. If the no cointegration null is not rejected, we conclude that the variables are non-cointegrated, and proceed no further. If the null is rejected, however, the testing proceeds by applying a panel unit root test to the dependent variable. If the unit root null is not rejected, we conclude that there is cointegration, while, if it is rejected, we conclude that there is no cointegration, and that the variables are stationary in their levels. 


\subsection{Simulation results}

In this section, we evaluate the small-sample properties of the Durbin-Hausman tests. For this purpose, a small set of simulation experiments were conducted using (7) through (11) to generate the data.

For simplicity, the errors $w_{i t}, u_{t}$ and $v_{i t}$ are all drawn from $N(0,1)$, and we assume that $\beta_{i}=1, \phi_{i}=\phi$ and $\delta_{i}=\delta$ for all $i$ while $\alpha_{i} \sim N(0,1)$. Also, different values of $\rho_{j}$ did not affect the results much, and we therefore set $\rho_{j}$ to zero for all $j$. The data is generated for 1,000 panels with $T+50$ time series observations, where the first 50 is disregarded to reduce the effect of the initial values, which are all set equal to zero.

In implementing the Durbin-Hausman tests, we must determine $k_{\max }$, the maximum for the estimation of the number of common factors. Different choices did not alter the results so we set $k_{\max }$ to five. We must also determine the appropriate kernel bandwidth $M_{i}$ to handle the serial correlation. Although this can in principle be done using a data dependent rule, such as the automatic procedure of Newey and West (1994), in this section we chose $M_{i}$ as a function of $T$, which is computationally less demanding. ${ }^{10}$ In particular, since there is no obvious choice, we chose $M_{i}$ to the largest integer less than $4(T / 100)^{2 / 9}$.

For comparison, the tests of Pedroni (2004) are also simulated, which is interesting because these are the tests that are most likely to be used by other researchers. ${ }^{11}$ To this effect, we shall use $\widetilde{Z}_{t}$ and $\widetilde{Z}_{\rho}$ to denote his group mean $t$-ratio and coefficient type tests. The corresponding panel tests are denoted $Z_{t}$ and $Z_{\rho}$, respectively. Pedroni (2004) also develops a panel variance ratio test, which we will denote by $Z_{v}$. As with $D H_{p}$ and $D H_{g}$, the panel and group mean tests of Pedroni (2004) differ in that while the former presumes a common autoregressive root under the alternative, the latter does not. For brevity, we report only the size and size-adjusted power on the nominal $5 \%$ level. Computational work was performed in GAUSS.

Consider first the results in Table 1 on the size and power of the tests when $\delta=1$, so the regressor is nonstationary, and the slope is not predetermined. In large samples, all tests should have a rejection frequency of $5 \%$ when $\phi=$ 1 and the null is true. The table reveals that the new tests appear to be reasonably sized for all values of $\lambda_{i}$, which corroborate the asymptotic theory that these tests should be independent of the common component. As expected, the size accuracy increases as both $N$ and $T$ grow. The Pedroni (2004) tests are also reasonably sized when $\lambda_{i}=0$, but can be severely distorted when $\lambda_{i}$ is nonzero. In fact, setting $\lambda_{i} \sim N(1,1)$ almost uniformly results in the size going

\footnotetext{
${ }^{10}$ In Section 4, we show how to implement the tests based on the Newey and West (1994) procedure.

${ }^{11}$ Another interesting comparison would be to consider defactored versions of the Pedroni (2004) tests. Such an approach was recently taken by Gengenbach et al. (2006), who propose using a two-step Bai and Ng (2004) type procedure in order to make the Pedroni (2004) tests robust against cross-section dependence. Their results suggest that the tests generally perform well in small-samples.
} 
to unity. In addition, we see that there is a strong tendency for the distortions to accumulate and to get very serious as $N$ increases. ${ }^{12}$

As for the power of the tests, Table 1 shows that there can be large advantages to using the Durbin-Hausman tests. These advantages appear to be particularly striking when $\phi$ lies in the vicinity of unity. This leads us to the conclusion that the new tests should be very well suited for testing the Fisher effect, which, as argued in Section 2, is likely to involve errors that are nonstationary under the null and highly persistent under the alternative. We also see that the power advantage appears to be larger when $N$ and $T$ are small, as is usually the case in applications.

As in most other studies, all results reported so far are for the typical cointegration test setting with a nonstationary regressor and a slope that is estimated. This makes it interesting to also consider deviations from this classical setting. Table 2 contains some simulation results for the scenario when $\delta<1$, so the regressor is stationary. Because it is no longer meaningful to talk about power when the regressor is stationary, we only simulate the size of the tests.

As expected, the Durbin-Hausman tests continues to perform well with good size accuracy in most experiments. By contrast, for the Pedroni (2004) tests, which are not equipped to deal with stationary regressors, we see that there is a strong tendency to underreject the null. Thus, the presence of a stationary regressor makes these these tests more conservative. The results for the scenario with a predetermined slope are reported in Table 3. It is seen that while the tests tend to perform well when the slope is correctly specified, the power falls markedly if it is misspecified, which is to be expected. Another expected result is that the power with a correctly specified slope is higher than when the slope is estimated, as seen by comparing Tables 1 and 3 .

The results on the estimated number of common factors are not reported but we briefly describe them. Consistent with the results documented by Bai and $\mathrm{Ng}$ (2004), we find that the true number of factors is chosen with high probability under both the null and alternative hypotheses. In fact, only in a hand full of cases is this probability less than one.

In summary, we find that the Durbin-Hausman tests show higher power than the other tests considered and, at the same time, maintain the nominal size well in small samples. ${ }^{13}$ Since the power advantage is particularly striking in small panels with highly autoregressive errors, this leads us to the conclusion that the new tests should be particularly well suited for testing the Fisher effect. This conclusion is further strengthened by the fact that the tests seem to perform

\footnotetext{
${ }^{12}$ Pedroni (2004) suggests demeaning the data with respect to a common time effect to permit for at least some cross-sectional dependence. In accordance with the results reported by Westerlund (2005), however, this did not seem to work very well, and we therefore only report the results with no common time effect.

${ }^{13}$ It should be noted that, although we have used the tests of Pedroni (2004) for our comparison, similar results are expected for all panel cointegration tests that do not permit for cross-section dependence or stationary regressors.
} 
well even in the presence of cross-sectional dependence, stationary regressors and a predetermined cointegration vector.

\section{Empirical results}

In this section, we employ the Durbin-Hausman tests to obtain new empirical evidence on the Fisher effect. For this purpose, data covering 20 OECD countries between the first quarter of 1980 and the fourth quarter of 2004 are obtained from the OECD data bases Economic Outlook and Main Economic Indicators. ${ }^{14}$ The data is quarterly and include for each country a short-term nominal interest rate and the consumer price index. Both variables are measured at annual rates in percentages.

We begin by presenting the evidence on the partial Fisher effect, which involves testing whether the nominal interest and inflation rates are indeed nonstationary and cointegrated. In so doing, with the possibility of inflation being stationary, we begin by testing for cointegration, as described earlier. If the null of no cointegration is not rejected, we conclude that there is no Fisher effect and proceed no further, while if it is rejected, we go on by testing for unit roots. If the null of a unit root in the nominal interest rate is not rejected, the variables are deemed cointegrated, in which case the partial Fisher effect holds. Having presented the evidence on the partial Fisher effect, we then go on to discuss the evidence on the full effect, which, in addition to the partial effect, requires testing whether the estimated relationship is in fact one-for-one.

\subsection{The partial Fisher effect}

As argued in Section 2, in the presence of unit roots, the Fisher effect necessitates that the nominal interest rate and inflation be cointegrated. The first step in our empirical analysis is therefore to test for cointegration.

We begin by considering some evidence on the individual country level. To this end, we employ the well-known $A D F$ and $\widehat{P}_{u}$ tests developed by Phillips and Ouliaris (1990), which both take no cointegration as the null hypothesis. Consistent with our specification of the Fisher equation, the estimated test regression is fitted with a constant term only. As with the Durbin-Hausman tests, $A D F$ and $\widehat{P}_{u}$ needs to be corrected to account for the effects serial correlation, which requires the choice of a bandwidth or a lag length parameter. For the $\widehat{P}_{u}$ test, which is based on a semiparametric kernel correction, we use the Newey and West (1994) automatic bandwidth selection procedure, while for the $A D F$ test, which uses a parametric correction, we use the Campbell and Perron (1991) lag length selection procedure with a maximum of 10 lags. These procedures will be used throughout this section whenever a bandwidth or a lag length parameter needs to be chosen, and will not be discussed any further.

\footnotetext{
${ }^{14}$ See Table 1 for a complete list of the countries considered.
} 
The results for the individual $A D F$ and $\widehat{P}_{u}$ tests are presented in Table 4 . In agreement with the results of Strauss and Terrell (1995), Koustas and Serletis (1999), Ghazali and Ramlee (2003) and Atkins and Serletis (2003), to mention a few, we see that the null hypothesis of no cointegration cannot be rejected for any of the countries on any conventional level of significance. Thus, these results strongly suggest that we should reject the Fisher effect.

As pointed out in Section 2, however, time series tests of this sort are likely to suffer from deficient power as the regression errors in the Fisher equation are expected to be highly persistent under the alternative hypothesis of cointegration. For this reason, we now provide some evidence based on panel data. We begin by considering some preliminary results obtained by using the Pedroni (2004) tests analyzed earlier in the simulations. These are presented in Table 5. Except for $Z_{v}$, which results in a nonrejection on the $5 \%$ level, we see that the null of no cointegration can be safely rejected on all conventional significance levels. Although indicative of a partial Fisher effect, we know from Section 3 that inference based on these tests can be severely deceptive unless the data is cross-sectionally independent.

To get a feeling of the size of this problem in the OECD data, we computed the long-run cross-sectional correlation matrix of the OLS residuals obtained from the estimated Fisher equation. The results, which are not reported for space considerations, point to clear violations of the cross-sectional independence assumption. In fact, the pairwise correlations are never smaller than 0.24 with an overall average of 0.71. As expected, the largest correlations are observed among the European countries. United States stands out as having the smallest correlations.

These results suggest that the assumption of cross-sectional independence is likely to be violated, and that there is a need to allow for dependence among the cross-sectional units. Therefore, we now employ the Durbin-Hausman tests. The results reported in Table 5 suggest that we are able to strongly reject the null hypothesis on all conventional significance levels, which corroborates our preliminary evidence based on the Pedroni (2004) tests. ${ }^{15}$ Even though these results can only be taken as evidence in favor of a partial Fisher effect, we also see that the no cointegration null is rejected even if the cointegrating slope is fixed at unity as postulated by the Fisher effect. Thus, we also have some evidence of the full Fisher effect.

Of course, since the integratedness of the variables is not yet known, these results should be interpreted with caution as the possibility remains that the estimated regression is stationary. In order to shed some light on this, we now proceed by testing the variables for unit roots. As in the cointegration analysis, we begin by considering the evidence on the individual country level.

\footnotetext{
${ }^{15}$ To guard against possible violations of strict exogeneity, some test results based on (7) augmented with lags and leads of $\Delta \pi_{i t}$ were also obtained. However, since the conclusions were not altered, these results are not reported.
} 
The two tests that we use are both based on the augmented Dickey and Fuller (1979) principle, and therefore take a unit root as the null hypothesis. The first test, denoted $\tau_{\mu}$, is based on using conventional OLS demeaning, while the second, denoted $\widetilde{\tau}_{\mu}$, is based on generalized OLS demeaning, as suggested by Elliott et al. (1996). The reason for using two tests is that $\tau_{\mu}$ may be biased in small samples when the series is local to unity. As pointed out earlier, this is likely to be particularly relevant when testing the Fisher effect as the unit root component of inflation can sometimes be weak. To account for this, we also employ the $\widetilde{\tau}_{\mu}$ test.

The results on the individual unit root tests are reported in Table 4 . The results suggest that the null of a unit root cannot be rejected for any of the countries on any conventional significance level when using the $\widetilde{\tau}_{\mu}$ test. Although the $\tau_{\mu}$ test generally results in more significant values, the overall picture is that there is little evidence against the unit root null, which coincide largely with most unit root evidence on the OECD countries. For example, Koustas and Serletis (1999) use quarterly data on 11 OECD countries covering approximately the period 1957 to 1995 . Consistent with our results, they are unable to reject unit root null for any of the countries. Similar results have been reported by for example Engsted (1995), Strauss and Terrell (1995) and Atkins and Serletis (2003).

The unit root results on the individual country level provide strong evidence to suggest that the nominal interest rate and inflation are nonstationary, as required for the Fisher effect. However, it is well known that time series tests of this sort can have low power against plausible stationary alternatives unless the time series is very long. Furthermore, the way in which classical hypothesis testing is carried out ensures that the null hypothesis will not be rejected unless there is very strong evidence against it. Thus, a failure to reject the unit root null does not definitely establish the presence of a unit root.

A natural way to increase power is to exploit the cross-sectional information on the unit root hypothesis by using tests that are based on panel data. In a recent study, Smith et al. (2004) develop several panel data unit root tests that are based on the sieve bootstrap approach, which uses the fact that the time series dependence of the data can be approximated by means of a finite ordered autoregressive model. To also preserve the cross-sectional dependence, the bootstrap innovations are drawn from the joint cross-sectional distribution on the estimated residuals. The tests that we consider are denoted $\bar{t}, \overline{L M}$, $\overline{\max }$ and $\overline{\min }$. These are all group mean type tests of the null hypothesis of a unit root, which permit the individual autoregressive roots to differ under the alternative hypothesis.

The results based on 5,000 bootstrap replications are reported in Table 6 . It is seen that the null can be rejected at the $1 \%$ level for all tests, which corroborates the results on the individual country level. We therefore conclude that the variables appear to be nonstationary, which, together with our cointegration 
test results, implies that partial Fisher effect cannot be rejected.

The next step in our empirical analysis is to infer the full version of the Fisher effect by testing whether the long-run relationship between the inflation and nominal interest rates is indeed one-for-one.

\subsection{The full Fisher effect}

It is well known that the OLS estimator is consistent under fairly general conditions when applied to the cointegrated regression in (7). If $v_{i t}$ and $w_{i t}$ are correlated, however, then this induces nuisance parameters in the asymptotic distribution of the OLS estimator, which then falls outside the local asymptotic mixture of normals family. To account for both of these features, we employ the dynamic OLS (DOLS) estimator of Saikkonen (1991) and the fully modified OLS (FMOLS) estimator of Phillips and Hansen (1990).

Both estimators are asymptotically equivalent and fully efficient in the presence of serially correlated errors and endogenous regressors. The difference between them lies in the methods undertaken in order to ensure efficiency of the cointegration parameters. Specifically, while DOLS employs a parametric correction whereby lags and leads of $w_{i t}$ are introduced, FMOLS adjusts for the temporal dependencies of the data by directly estimating the various nuisance parameters semiparametrically. We use two lags and leads of $w_{i t}$ to construct the DOLS, whereas the FMOLS is based on the same Bartlett kernel used for the unit root and cointegration tests.

The results on the estimated slope parameters are reported in Table 7 together with the double-sided $p$-values for the unit slope hypothesis. We begin by considering the results on the individual country level, in which case we see that the estimated slopes generally lie close to their hypothesized value of one. The range of the estimated slopes is 0.324 to 1.204 for the OLS, 0.601 to 1.771 for the DOLS and 0.544 to 1.475 for the FMOLS. The closeness of these estimates to their expected value based on the Fisher effect is supported by the $p$-values. Indeed, by looking at the $p$-values based on the normal distribution, we see that the null hypothesis of a unit slope is rarely rejected at the $1 \%$ level. In fact, the null is rejected five times for the OLS, three times for the DOLS and only one time for the FMOLS.

These results give a strong overall support for the full Fisher effect, and are consistent with much of the recent evidence in the literature. Take for example the study of Berument and Jelassi (2002), who examine a panel of monthly data spanning roughly the period 1957 to 1998 across 26 countries. Among the 12 OECD member countries considered, the authors can only reject the hypothesis of a unit slope on the $5 \%$ level on three occasions, for France, Korea and United Kingdom. Similarly, Engsted (1995) uses a panel of quarterly data covering 12 OECD countries between 1962 and 1993. He is unable to reject the unit slope hypothesis for any of the countries at the $1 \%$ level.

Consider next the panel estimation results reported at the bottom of Table 7 . 
There are two types of estimators, which we will describe here briefly. For more details, we make reference to Pedroni $(2000,2001)$. The within estimators are based on the panel principle, and are appropriate for testing the null hypothesis that $\beta_{i}=1$ for all $i$ against the alternative hypothesis that $\beta_{i}=\beta$ and $\beta \neq 1$ for all $i$. The between estimators, on the other hand, are based on the group mean principle and are designed to test the null that $\beta_{i}=1$ for all $i$ versus the alternative that $\beta_{i} \neq 1$ for some $i$. Accordingly, the between estimators provide a consistent test of the common unit slope hypothesis against slope values that need not be common under the alternative hypothesis, while the within estimators do not.

In our case, since there is no reason to believe that the slopes will take on some other arbitrary common value if they are not equal to one, the between estimators stand out as the most natural choice. Furthermore, if the true slopes are not equal, the between estimators provide consistent estimates of the sample mean of the individual slopes, while the within estimators do not.

Consistent with the individual country regressions, we see that the pooled slopes are close to one and that the null of a unit slope cannot be rejected on the $5 \%$ level when using the normal distribution for any of the estimators. To test whether the imposed homogeneity restriction is in fact consistent with the data, we conduct a series of Wald tests on the estimated cointegration vectors. The results, which are presented in the bottom row of Table 7 , suggest that the null hypothesis of equal slopes must be rejected for all three estimators when using the asymptotic chi-squared $p$-value. This suggests that, although the between estimates are still interpretable in an average sense, the within estimates should be taken with some caution.

In agreement with the results of for example Mishkin (1992), Crowder and Hoffman (1992) and Evans and Lewis (1995), we observe some cases where the estimated slope is significantly less than one. This corroborates the Mundell (1963) and Tobin (1965) story that higher inflation encourages economic agents to substitute money balances for interest bearing assets, which drives asset prices up and real interest rates down, thus preventing nominal rates from raising enough to compensate for the increased inflation.

This is important because it implies that the ex ante real interest rate is nonstationary, which is inconsistent with the full Fisher effect. To appreciate this, note from (5) that the unit root component of the ex post real rate is $-\left(1-\beta_{i}\right)$ times inflation. Thus, a unit positive permanent shock to inflation translate into a permanent shock in the ex post real rate of magnitude $-\left(1-\beta_{i}\right)$. Since $\beta_{i}$ is negative in this case, a positive shock to inflation correspond to a negative shock to the ex post real rate. From (4) we see that the ex ante rate can be decomposed into the ex post rate plus the regression error from (5). It follows that if ex post rate is nonstationary, then so is the ex ante rate.

Consequently, an estimated slope significantly less than one is not compatible with the full Fisher effect. Hence, based on the $p$-values from the asymptotic 
normal distribution, the full Fisher effect must be rejected at the $1 \%$ level for eight of the 20 countries, for Belgium, Canada, Switzerland, Germany, United Kingdom, Ireland, Japan and Portugal. As argued by Crowder and Hoffman (1996) and Caporale and Pittis (2004), however, a less than unit slope may not reflect the actual data generating process but rather a downward endogeneity bias on the part of the estimators employed. If this is the case, inference based on the normal distribution could be misleading.

To investigate this possibility, we engage in a small simulation exercise where the data generating process is chosen to mimic the endogeneity structure of the data. For simplicity, we disregard any endogeneity that may run between the individual regressions, and focus instead on capturing the effect within each regression. As in Section 3.4, the data is generated according to (7) through (11). This time, however, we make the assumption that the vector $\left(v_{i t}, w_{i t}\right)^{\prime}$ has a joint distribution, which will enable us to model the endogeneity through the correlation between $v_{i t}$ and $w_{i t}$. In particular, following Caporale and Pittis (2004), we shall assume that $\left(v_{i t}, w_{i t}\right)^{\prime}$ follows the first order vector autoregression normally distributed innovations. For simplicity, we assume that inflation is strictly nonstationary and that there are no common factors.

The first step in the simulations is to use the observed OECD data to estimate the parameters of the data generating mechanism. These estimates are then used to generate simulated data according to (7) through (11) while imposing the null hypothesis of a unit slope. In particular, we obtain 1,000 panels of the same size as ours, which are then used to compute the size of a double-sided $5 \%$ level $t$-test of the hypothesis of a unit slope as well as the bias and root mean squared error of the estimated slopes themselves. The mean of the $t$-statistics is also reported.

The results are reported in Table 8. There are two important results that we would like to point out. First, all three estimators are severely downwards biased with the OLS estimator being the most biased. Second, the distributions of the $t$-ratios are highly non-central and shifted to the left. Notably, the averages of the $t$-ratios are -3.964 for the OLS, -2.827 for the DOLS and -3.204 for the FMOLS, which is indicative of large size distortions. Indeed, the averages of the individual rejection frequencies based on the $5 \%$ critical value from the normal distribution are 0.78 for the OLS, 0.64 for the DOLS and 0.655 for the FMOLS. Thus, inference based on the asymptotic normal $p$-values reported in Table 7 is likely to be highly deceptive.

Valkanov (2003) suggests another reason as to why inference based on the normal distribution is likely to be inappropriate when testing the unit slope hypothesis. He argues that the use of time aggregated data, as is the case with compounded interest rate series, may alter the convergence rate of routinely computed $t$-ratios with massive size distortions as a result.

One possible solution to these problems is to employ the bootstrap, which makes inference possible by using the empirical distribution of the $t$-statistics. 
The particular bootstrap opted for this section is taken from Chang et al. (2006), who propose a sieve resampling scheme that preserves the serial correlation properties of the errors, and that can be generalized along the lines of Smith et al. (2004) to also accommodate cross-sectional dependency.

We apply this bootstrap approach to the OECD data using 5,000 bootstrap replications. The bootstrapped $p$-values are presented in Table 7 . In contrast to our earlier conclusion using inference based on the $p$-values obtained from the asymptotic normal distribution, we are now unable to reject the unit slope hypothesis for any of the countries on the $1 \%$ level. We also see that the null hypothesis of a common cointegrating slope cannot be rejected for any of the estimators when using the bootstrapped $p$-values for the Wald tests, and that the panel estimates in turn are not significantly different from one. Hence, we cannot reject the full Fisher effect for any of the countries nor for the panel as a whole.

To test the robustness of this conclusion, we repeated the empirical analysis based on both monthly and annual OECD data. Some additional estimates were also obtained using the yield on long-term government bonds as interest rate. For brevity, however, we do not report these results but we briefly describe them. Regardless of sample frequency, the null of no cointegration is still rejected when using the panel tests. The full Fisher effect is also supported using the bootstrapped $p$-values. The results obtained using long-term interest rates are qualitatively similar.

\section{Conclusions}

Recent empirical studies suggest that the Fisher effect, stating that inflation and nominal interest rates should cointegrate with a unit slope parameter on inflation, do not hold, a finding at odds with many theoretical models. This paper argues that these results can be explained in part by the low power inherent in univariate cointegration tests and that the use of panel data should generate more powerful tests. The importance of using panel data rather than single time series stems from the fact that the Fisher equation is likely to involve errors that are highly persistent even though we have cointegration. If this is the case, then the information content of a single time series may be insufficient to reject that cointegration is absent.

In this paper we investigate the Fisher effect using a panel of quarterly data covering the period 1980 to 2004 on 20 OECD countries. Preliminary results suggest that both inflation and interest rates exhibit features that are common across countries and that there is a need to allow for cross-sectional dependence. However, this allowance invalidates inference based on most existing panel cointegration tests, which rely critically on assuming that the cross-sectional units are independent of each other.

The approach used in this paper is to model this dependence using a small 
number of common factors. Conditional on these factors, the cross-sectional units are assumed to be independent, though the remaining idiosyncratic error term may be serially correlated. With these assumptions in mind, we derive two tests based on the Durbin-Hausman principle that are designed to test the null hypothesis of no cointegration against the alternative hypothesis of cointegration. The limiting distributions of our tests are shown to be normal and therefore no special table of critical values is required. Results from a small Monte Carlo study suggest that the tests have small size distortions and greater power than other popular panel cointegration tests.

Another advantage with the new tests is that they are robust against the presence of stationary regressors, which is highly relevant in our application as there is considerable doubt as to the integratedness of inflation. Yet another advantage is that the tests can be readily implemented using a predetermined cointegration vector without affecting the asymptotic null distributions. This is important because if the Fisher effect holds, then a test for cointegration with a unit slope imposed will be more efficient than a test based on an estimated slope.

The aim of the empirical part of the paper is to show that a failure to reject the absence of cointegration for an individual country need not be taken as evidence against the Fisher effect, and that the use of panel data can lead to more accurate tests. The way we do this is to first show that the null of no cointegration cannot be rejected at conventional significance levels when using data on individual countries, and that this can in part be attributed to the low power of the methodology used. We then show that the same null can be safely rejected when using our panel data approach. As a final touch, we also provide bootstrap evidence to suggest that the hypothesis of a unit slope on inflation cannot be rejected for any of the individual countries nor for the panel as a whole.

Of course, although our results show that an absence of cointegration on the individual country level need not be taken as evidence against the Fisher effect, one should be careful in generalizing these too broadly. In particular, a nonrejection of the Fisher effect does not necessarily imply that the Fisher effect holds. Nevertheless, the results clearly illustrate the need for more powerful tests when analyzing the extent of the Fisher effect using cointegration based methods. 


\section{Appendix: Mathematical proofs}

In this appendix, we prove asymptotic null distributions of Durbin-Hausman test statistics. For convenience, we will make frequent use of the notation $\left(x_{i t}\right)_{p}$ to indicate the projection of $x_{i t}$ onto $\Delta \pi_{i t}$. Thus, $\left(x_{i t}\right)_{p}=\Delta \pi_{i t} b_{i}$, where $b_{i}$ is the estimated projection parameter. Also, since the common factor $F_{t}$ can only be identified up to a scale matrix $H$, say, we consider the rotation $H F_{t}$ of $F_{t}$, see Bai and $\mathrm{Ng}$ (2004). Throughout, we assume that the necessary regulatory conditions for the relevant asymptotic theory to apply are satisfied.

Lemma A.1. Under Assumptions 1 through 3 , for $\phi_{i}=1$ or $\phi_{i}<1$ and $\delta_{i}=1$, as $T \rightarrow \infty$
(a) $T^{-1 / 2} \sum_{j=2}^{t} \Delta \pi_{i j}=O_{p}(1)$;
(b) $T^{-1 / 2} \sum_{t=2}^{T} \Delta \pi_{i t} \Delta F_{t}=O_{p}(1)$;
(c) $T^{-1 / 2} \sum_{t=2}^{T} \Delta \pi_{i t} \Delta e_{i t}=O_{p}(1)$;
(d) $T^{-1} \sum_{t=2}^{T}\left(\Delta \pi_{i t}\right)^{2}=O_{p}(1)$.

\section{Proof of Lemma A.1}

Because $\Delta \pi_{i t}=w_{i t}$ if $\delta_{i}=1$, (a) is a direct consequence of Assumption 2. For parts (b) and (c), we use Assumptions 1 (c) and 3 (b), which ensure that $u_{t}$, $w_{i t}$ and $v_{i t}$ are mutually independent so that $T^{-1 / 2} \sum_{t=2}^{T} \Delta \pi_{i t} \Delta F_{t}=O_{p}(1)$ and $T^{-1 / 2} \sum_{t=2}^{T} \Delta \pi_{i t} \Delta e_{i t}=O_{p}(1)$ as $T \rightarrow \infty$. Finally, to prove (d), we make use of Assumption 1 (d), from which it follows that $T^{-1} \sum_{t=2}^{T}\left(\Delta \pi_{i t}\right)^{2} \rightarrow_{p} \Omega_{i}$ as $T \rightarrow \infty$.

Lemma A.2. Under the conditions of Lemma A.1, with $\delta_{i}<1$, as $T \rightarrow \infty$

(a) $\sum_{j=2}^{t} \Delta \pi_{i j}=O_{p}(1)$;

(b) $T^{-1 / 2} \sum_{t=2}^{T} \Delta \pi_{i t} \Delta F_{t}=O_{p}(1)$;

(c) $T^{-1 / 2} \sum_{t=2}^{T} \Delta \pi_{i t} \Delta e_{i t}=O_{p}(1)$;

(d) $T^{-1} \sum_{t=2}^{T}\left(\Delta \pi_{i t}\right)^{2}=O_{p}(1)$.

\section{Proof of Lemma A.2}

With $\delta_{i}<1, \sum_{j=2}^{t} \Delta \pi_{i j}=\delta_{i}^{t} \pi_{i 0}+\sum_{j=0}^{t-1} \delta_{i}^{j} w_{i t-j}$, which has mean zero and variance $\Omega_{i} /\left(1-\delta_{i}^{2}\right)$. Thus, $\sum_{j=2}^{t} \Delta \pi_{i j}=O_{p}(1)$ as required for (a). The proof for parts (b), (c) and (d) are identical to that of Lemma A.1. 
Lemma A.3. Let $C_{N T}=\min \{\sqrt{T}, \sqrt{N}\}$ and $D_{N T}=\min \{\sqrt{T}, N\}$. Under the conditions of Lemma A.1, with $\delta_{i}=1$ or $\delta_{i}<1$, as $N, T \rightarrow \infty$
(a) $T^{-1 / 2} \widehat{F}_{t}=T^{-1 / 2} H F_{t}+O_{p}\left(C_{N T}^{-1}\right)$;
(b) $T^{-1 / 2} \widehat{e}_{i t}=T^{-1 / 2} e_{i t}+O_{p}\left(C_{N T}^{-1}\right)$;
(c) $T^{-1} \sum_{t=2}^{T}\left(\Delta \widehat{e}_{i t}\right)^{2}=T^{-1} \sum_{t=2}^{T}\left(\Delta e_{i t}\right)^{2}+O_{p}\left(C_{N T}^{-2}\right)$;
(d) $T^{-1} \sum_{t=2}^{T} \widehat{e}_{i t-1} \Delta \widehat{e}_{i t}=T^{-1} \sum_{t=2}^{T} e_{i t-1} \Delta e_{i t}+O_{p}\left(C_{N T}^{-2}\right)$;
(e) $T^{-2} \sum_{t=2}^{T} \widehat{e}_{i t}^{2}=T^{-1} \sum_{t=2}^{T} e_{i t}^{2}+O_{p}\left(D_{N T}^{-1}\right)$.

\section{Proof of Lemma A.3}

We begin with (a). Let $\Delta \widehat{F}_{t}=H \Delta F_{t}+v_{t}$ for some $v_{t}$. Hence, since $\widehat{F}_{1}=0$ by definition, it follows that

$$
\begin{aligned}
T^{-1 / 2} \widehat{F}_{t} & =T^{-1 / 2} \sum_{j=2}^{t} \Delta \widehat{F}_{j} \\
& =T^{-1 / 2} \sum_{j=2}^{t} H \Delta F_{j}+T^{-1 / 2} \sum_{j=2}^{t} v_{j} .
\end{aligned}
$$

But $F_{1}=O_{p}(1)$ so the first term on the right-hand side is

$$
T^{-1 / 2} \sum_{j=2}^{t} \Delta F_{j}=T^{-1 / 2}\left(F_{t}-F_{1}\right)=T^{-1 / 2} F_{t}+O_{p}\left(T^{-1 / 2}\right) .
$$

The second term is $O_{p}\left(C_{N T}^{-1}\right)$ by equation (A.3) of Bai and Ng (2004). This implies (a) as can be seen by writing

$$
T^{-1 / 2} \widehat{F}_{t}=T^{-1 / 2} H F_{t}+O_{p}\left(C_{N T}^{-1}\right) .
$$

Consider (b). From the text, we have that the defactored and first differentiated residuals can be written as

$$
\Delta \widehat{e}_{i t}=\Delta \widehat{z}_{i t}-\widehat{\lambda}_{i}^{\prime} \Delta \widehat{F}_{t}
$$

where

$$
\begin{aligned}
\Delta \widehat{z}_{i t} & =\Delta i_{i t}-\widehat{\beta}_{i} \Delta \pi_{i t}=\Delta i_{i t}-\left(\Delta i_{i t}\right)_{p}=\Delta z_{i t}-\left(\Delta z_{i t}\right)_{p} \\
& =\lambda_{i}^{\prime} \Delta F_{t}+\Delta e_{i t}-\left(\lambda_{i}^{\prime} \Delta F_{t}+\Delta e_{i t}\right)_{p} .
\end{aligned}
$$

Thus, (A2) can be written

$$
\Delta \widehat{e}_{i t}=\lambda_{i}^{\prime} \Delta F_{t}+\Delta e_{i t}-\left(\lambda_{i}^{\prime} \Delta F_{t}+\Delta e_{i t}\right)_{p}-\widehat{\lambda}_{i}^{\prime} \Delta \widehat{F}_{t}
$$


By using some algebra, this expression can be restated as

$$
\begin{aligned}
\Delta \widehat{e}_{i t} & =\Delta e_{i t}-\left(\lambda_{i}^{\prime} \Delta F_{t}+\Delta e_{i t}\right)_{p}+\lambda_{i}^{\prime} H^{-1} H \Delta F_{t}-\lambda_{i}^{\prime} H^{-1} \Delta \widehat{F}_{t} \\
& +\Delta \lambda_{i}^{\prime} H^{-1} \widehat{F}_{t}-\widehat{\lambda}_{i}^{\prime} \Delta \widehat{F}_{t} \\
& =\Delta e_{i t}-\left(\lambda_{i}^{\prime} \Delta F_{t}+\Delta e_{i t}\right)_{p}-\lambda_{i}^{\prime} H^{-1}\left(\Delta \widehat{F}_{t}-H \Delta F_{t}\right) \\
& -\left(\widehat{\lambda}_{i}-H^{-1 \prime} \lambda_{i}\right)^{\prime} \Delta \widehat{F}_{t} \\
& =\Delta e_{i t}-\left(\lambda_{i}^{\prime} \Delta F_{t}+\Delta e_{i t}\right)_{p}-\lambda_{i}^{\prime} H^{-1} v_{t}-d_{i}^{\prime} \Delta \widehat{F}_{t}
\end{aligned}
$$

where $d_{i}=\widehat{\lambda}_{i}-H^{-1 \prime} \lambda_{i}$. By taking partial sums, and by using that $\widehat{e}_{i 1}=0$ by definition, we get

$$
\begin{aligned}
T^{-1 / 2} \widehat{e}_{i t} & =T^{-1 / 2} \sum_{j=2}^{t} \Delta \widehat{e}_{i j} \\
& =T^{-1 / 2} \sum_{j=2}^{t} \Delta e_{i j}-T^{-1 / 2} \sum_{j=2}^{t}\left(\lambda_{i}^{\prime} \Delta F_{t}+\Delta e_{i t}\right)_{p}-\lambda_{i}^{\prime} H^{-1} T^{-1 / 2} V_{t} \\
& -d_{i}^{\prime}\left(T^{-1 / 2} \sum_{j=2}^{t} \Delta \widehat{F}_{j}\right) \\
& =T^{-1 / 2} \sum_{j=2}^{t} \Delta e_{i j}-I-I I-I I I, \text { say. }
\end{aligned}
$$

Here $V_{t}$ is the partial sum of $v_{t}$, which is such that

$$
\widehat{F}_{t}=H F_{t}-H F_{1}+\sum_{j=2}^{t} v_{j}=H F_{t}-H F_{1}+V_{t} .
$$

Moreover, making use of (A.3) in Bai and $\mathrm{Ng}$ (2004), part II must be $O_{p}\left(C_{N T}^{-1}\right)$. For part $I I I$, we use (a), which implies that

$$
T^{-1 / 2} \sum_{j=2}^{t} \Delta \widehat{F}_{j}=T^{-1 / 2} \sum_{j=2}^{t} H \Delta F_{j}+O_{p}\left(C_{N T}^{-1}\right)=O_{p}(1) .
$$

But $d_{i}=O_{p}\left(D_{N T}^{-1}\right)$ by Lemma 1 (c) of Bai and $\mathrm{Ng}(2004)$ so $I I I$ is $O_{p}\left(D_{N T}^{-1}\right)$. For the remaining term, part $I$, we have

$$
\begin{aligned}
I & =T^{-1 / 2}\left(T^{-1 / 2} \sum_{j=2}^{t} \Delta \pi_{i j}\right)\left(T^{-1} \sum_{t=2}^{T}\left(\Delta \pi_{i t}\right)^{2}\right)^{-1} \\
& \cdot\left(\lambda_{i}^{\prime} T^{-1 / 2} \sum_{t=2}^{T} \Delta \pi_{i t} \Delta F_{t}+T^{-1 / 2} \sum_{t=2}^{T} \Delta \pi_{i t} \Delta e_{i t}\right) \\
& =T^{-1 / 2} O_{p}(1) O_{p}(1) O_{p}(1)
\end{aligned}
$$


where the second equality follows from Lemmas A.1 and A.2.

Putting everything together, since $\sum_{j=2}^{t} \Delta e_{i j}=e_{i t}-e_{i 1}$ and $e_{i 1}=O_{p}(1)$, (A5) reduces to

$$
\begin{aligned}
T^{-1 / 2} \widehat{e}_{i t} & =T^{-1 / 2} \sum_{j=2}^{t} \Delta e_{i j}+O_{p}\left(C_{N T}^{-1}\right)+O_{p}\left(T^{-1 / 2}\right) \\
& =T^{-1 / 2} e_{i t}+O_{p}\left(C_{N T}^{-1}\right) .
\end{aligned}
$$

This establishes (b).

Next, consider (c). Let $a_{i t}=\lambda_{i}^{\prime} H^{-1} v_{t}-d_{i}^{\prime} \Delta \widehat{F}_{t}$ and $b_{i t}=\left(\lambda_{i}^{\prime} \Delta F_{t}+\Delta e_{i t}\right)_{p}$, so that (A4) becomes $\Delta \widehat{e}_{i t}=\Delta e_{i t}-b_{i t}-a_{i t}$. This implies

$$
\begin{aligned}
T^{-1} \sum_{t=2}^{T}\left(\Delta \widehat{e}_{i t}\right)^{2} & =T^{-1} \sum_{t=2}^{T}\left(\Delta e_{i t}-b_{i t}-a_{i t}\right)^{2} \\
& =T^{-1} \sum_{t=2}^{T}\left(\Delta e_{i t}\right)^{2}+T^{-1} \sum_{t=2}^{T} b_{i t}^{2}+T^{-1} \sum_{t=2}^{T} a_{i t}^{2} \\
& -2 T^{-1} \sum_{t=2}^{T} \Delta e_{i t} b_{i t}-2 T^{-1} \sum_{t=2}^{T} \Delta e_{i t} a_{i t} \\
& -2 T^{-1} \sum_{t=2}^{T} a_{i t} b_{i t} \\
& =T^{-1} \sum_{t=2}^{T}\left(\Delta e_{i t}\right)^{2}+I+I I-I I I-I V-V, \text { say. }
\end{aligned}
$$

By using the same arguments as in Lemma B.1 of Bai and Ng (2004), part II is $O_{p}\left(C_{N T}^{-2}\right)$. Consider part III. By Lemmas A.1 and A.2, we have

$$
\begin{aligned}
I I I & =2 T^{-1}\left(T^{-1 / 2} \sum_{t=2}^{T} \Delta e_{i t} \Delta \pi_{i j}\right)\left(T^{-1} \sum_{t=2}^{T}\left(\Delta \pi_{i t}\right)^{2}\right)^{-1} \\
\cdot & \left(\lambda_{i}^{\prime} T^{-1 / 2} \sum_{t=2}^{T} \Delta \pi_{i t} \Delta F_{t}+T^{-1 / 2} \sum_{t=2}^{T} \Delta \pi_{i t} \Delta e_{i t}\right) \\
= & T^{-1} O_{p}(1) O_{p}(1) O_{p}(1),
\end{aligned}
$$

Hence, part $I I I$ is $O_{p}\left(T^{-1}\right)$ and, by similar arguments, so is $I$. For $V$, we use the Cauchy-Schwarz inequality, which implies

$$
\begin{aligned}
V & =2 T^{-1} \sum_{t=2}^{T} a_{i t} b_{i t} \leq 2\left(T^{-1} \sum_{t=2}^{T} a_{i t}^{2}\right)^{1 / 2}\left(T^{-1} \sum_{t=2}^{T} b_{i t}^{2}\right)^{1 / 2} \\
& =O_{p}\left(C_{N T}^{-1}\right) O_{p}\left(T^{-1 / 2}\right) .
\end{aligned}
$$


Finally, consider $I V$. This part might be written as

$$
\begin{aligned}
I V & =2 \lambda_{i}^{\prime} H^{-1} T^{-1} \sum_{t=2}^{T} \Delta e_{i t} v_{t}-2 d_{i}^{\prime} T^{-1} \sum_{t=2}^{T} \Delta e_{i t} \Delta \widehat{F}_{t} \\
& =2 d_{i}^{\prime} T^{-1} \sum_{t=2}^{T} \Delta e_{i t} \Delta \widehat{F}_{t}+O_{p}\left(C_{N T}^{-2}\right) \\
& =2 d_{i}^{\prime} T^{-1} \sum_{t=2}^{T} \Delta e_{i t}\left(\Delta \widehat{F}_{t}-H \Delta F_{t}\right)+2 d_{i}^{\prime} H T^{-1} \sum_{t=2}^{T} \Delta e_{i t} \Delta F_{t}+O_{p}\left(C_{N T}^{-2}\right),
\end{aligned}
$$

where the second equality follows by Lemma B.1 of Bai (2003). Let $\|a\|$ denote the Euclidean norm $\left(\operatorname{tr}\left(a^{\prime} a\right)\right)^{1 / 2}$ of the matrix $a$. By applying $\|a b\| \leq\|a|\|||b| \mid$ and the triangle inequality to the above expression, we get

$$
\begin{aligned}
|I V| & \leq 2\left\|d_{i}^{\prime}\right\| T^{-1} \sum_{t=2}^{T}\left\|\Delta e_{i t}\left(\Delta \widehat{F}_{t}-H \Delta F_{t}\right)\right\| \\
& +2\left\|d_{i}^{\prime} H\right\| T^{-1} \sum_{t=2}^{T}\left\|\Delta e_{i t} \Delta F_{t}\right\|+O_{p}\left(C_{N T}^{-2}\right),
\end{aligned}
$$

which, by applying the Cauchy-Schwarz inequality to the first term on the righthand side, reduces to

$$
\begin{aligned}
|I V| & \leq 2\left\|d_{i}^{\prime}\right\|\left(T^{-1} \sum_{t=2}^{T}\left(\Delta e_{i t}\right)^{2}\right)^{1 / 2}\left(T^{-1} \sum_{t=2}^{T}\left\|\Delta \widehat{F}_{t}-H \Delta F_{t}\right\|^{2}\right)^{1 / 2} \\
& +2\left\|d_{i}^{\prime} H\right\| T^{-1 / 2}\left(T^{-1 / 2} \sum_{t=2}^{T}\left\|\Delta e_{i t} \Delta F_{t}\right\|\right)+O_{p}\left(C_{N T}^{-2}\right) \\
& =O_{p}\left(D_{N T}^{-1}\right) O_{p}(1) O_{p}\left(C_{N T}^{-1}\right)+T^{-1 / 2} O_{p}\left(D_{N T}^{-1}\right) O_{p}(1)+O_{p}\left(C_{N T}^{-2}\right) .
\end{aligned}
$$

Here we have made use of the fact that $\|H\|=O_{p}(1)$ by construction, and Lemma A.1 of Bai (2003) from which it follows that

$$
T^{-1} \sum_{t=2}^{T}\left\|\Delta \widehat{F}_{t}-H \Delta F_{t}\right\|^{2}=O_{p}\left(C_{N T}^{-2}\right) .
$$

This implies that $I V$ is $O_{p}\left(C_{N T}^{-2}\right)$.

Combining the results, it is clear that (A6) reduces to

$$
T^{-1} \sum_{t=2}^{T}\left(\Delta \widehat{e}_{i t}\right)^{2}=T^{-1} \sum_{t=2}^{T}\left(\Delta e_{i t}\right)^{2}+O_{p}\left(C_{N T}^{-2}\right) .
$$

This proves (c). 
In order to prove (d) we use that $\widehat{e}_{i t}^{2}$ may be written as $\widehat{e}_{i t}^{2}=\left(\widehat{e}_{i t-1}+\Delta \widehat{e}_{i t}\right)^{2}=$ $\widehat{e}_{i t-1}^{2}+\left(\Delta \widehat{e}_{i t}\right)^{2}+2 \widehat{e}_{i t-1} \Delta \widehat{e}_{i t}$, from which it follows that

$$
\begin{aligned}
T^{-1} \sum_{t=2}^{T} \widehat{e}_{i t-1} \Delta \widehat{e}_{i t} & =2 T^{-1} \sum_{t=2}^{T}\left(\widehat{e}_{i t}^{2}-\widehat{e}_{i t-1}^{2}-\left(\Delta \widehat{e}_{i t}\right)^{2}\right) \\
& =2 T^{-1} \widehat{e}_{i T}^{2}-2 T^{-1} \widehat{e}_{i 1}^{2}-2 T^{-1} \sum_{t=2}^{T}\left(\Delta \widehat{e}_{i t}\right)^{2}
\end{aligned}
$$

Similarly, by applying the same trick to $e_{i t}^{2}$, we have

$$
T^{-1} \sum_{t=2}^{T} e_{i t-1} \Delta e_{i t}=2 T^{-1} e_{i T}^{2}-2 T^{-1} e_{i 1}^{2}-2 T^{-1} \sum_{t=2}^{T}\left(\Delta e_{i t}\right)^{2} .
$$

Now, it is clear from (b) that $T^{-1} \widehat{e}_{i T}^{2}=T^{-1} e_{i T}^{2}+O_{p}\left(T^{-1 / 2} C_{N T}^{-1}\right)$, while $\widehat{e}_{i 1}=0$ and $e_{i 1}=O_{p}(1)$ by assumption. Moreover, since the difference between the third terms on the right-hand side of (A7) and (A8) is $O_{p}\left(C_{N T}^{-2}\right)$ by (c), we can show that

$$
T^{-1} \sum_{t=2}^{T} \widehat{e}_{i t-1} \Delta \widehat{e}_{i t}=T^{-1} \sum_{t=2}^{T} e_{i t-1} \Delta e_{i t}+O_{p}\left(C_{N T}^{-2}\right) .
$$

This establishes part (d).

Finally, consider (e). Let $\widehat{e}_{i t}=e_{i t}-e_{i 1}-B_{i t}-A_{i t}$, where $B_{i t}$ and $A_{i t}$ are the cumulative sums of $b_{i t}$ and $a_{i t}$, respectively. This implies that

$$
\begin{aligned}
T^{-2} \sum_{t=2}^{T} \widehat{e}_{i t}^{2} & =T^{-2} \sum_{t=2}^{T}\left(e_{i t}-e_{i 1}-B_{i t}-A_{i t}\right)^{2} \\
& =T^{-2} \sum_{t=2}^{T} e_{i t}^{2}+T^{-2} e_{i 1}^{2}+T^{-2} \sum_{t=2}^{T} B_{i t}^{2}+T^{-2} \sum_{t=2}^{T} A_{i t}^{2} \\
& -2 T^{-2} \sum_{t=2}^{T} e_{i t} B_{i t}-2 T^{-2} \sum_{t=2}^{T} e_{i t} A_{i t}-2 T^{-2} \sum_{t=2}^{T} A_{i t} B_{i t} \\
& -2 e_{i 1}\left(T^{-2} \sum_{t=2}^{T} e_{i t}+T^{-2} \sum_{t=2}^{T} B_{i t}+T^{-2} \sum_{t=2}^{T} A_{i t}\right) \\
& =T^{-1} \sum_{t=2}^{T} e_{i t}^{2}+I+I I+I I I-I V-V-V I-V I I, \quad \text { say. (A9) }
\end{aligned}
$$


Now, $I$ is obviously $O_{p}\left(T^{-2}\right)$. Part $I I$ can be written as

$$
\begin{aligned}
I I & =T^{-1}\left(T^{-2} \sum_{t=2}^{T} \pi_{i t}^{2}\right)\left(T^{-1} \sum_{t=2}^{T}\left(\Delta \pi_{i t}\right)^{2}\right)^{-2} \\
& \cdot\left(\lambda_{i}^{\prime} T^{-1 / 2} \sum_{t=2}^{T} \Delta \pi_{i t} \Delta F_{t}+T^{-1 / 2} \sum_{t=2}^{T} \Delta \pi_{i t} \Delta e_{i t}\right)^{2} \\
& =T^{-1} O_{p}(1) O_{p}(1) O_{p}(1) .
\end{aligned}
$$

It follows that $I I$ is $O_{p}\left(T^{-1}\right)$, which is also true for part $I V$.

The next step is to show that $I I I$ is $O_{p}\left(C_{N T}^{-2}\right)$. In so doing, by first applying the triangle inequality and then $(a+b)^{2} \leq 2\left(a^{2}+b^{2}\right)$, we obtain

$$
\begin{aligned}
|I I I| & =T^{-2}\left\|\sum_{t=2}^{T}\left(\lambda_{i}^{\prime} H^{-1} V_{t}-d_{i}^{\prime} \widehat{F}_{t}\right)^{2}\right\| \\
& \leq 2 T^{-1}\left\|\lambda_{i}^{\prime} H^{-1}\right\|^{2}\left(T^{-1} \sum_{t=2}^{T}\left\|V_{t}\right\|^{2}\right)+2\left\|d_{i}\right\|^{2}\left(T^{-2} \sum_{t=2}^{T}\left\|\widehat{F}_{t}^{2}\right\|^{2}\right) \\
& =T^{-1} O_{p}(T / N)+O_{p}\left(D_{N T}^{-2}\right) O_{p}(1),
\end{aligned}
$$

where we have used equation (A.4) in Bai and Ng (2004), which says that

$$
T^{-1} \sum_{t=2}^{T}\left\|V_{t}\right\|^{2}=O_{p}(T / N) .
$$

Also, by their Lemma C.1, we have

$$
T^{-2} \sum_{t=2}^{T}\left\|\widehat{F}_{t}^{2}\right\|^{2}=O_{p}(1) .
$$

Furthermore, by using $I I, I I I$ and the Cauchy-Schwarz inequality, part $V I$ is $O_{p}\left(\left(\sqrt{T} C_{N T}\right)^{-1}\right)$, as can be seen by writing

$$
\begin{aligned}
V I & \leq 2\left(T^{-2} \sum_{t=2}^{T} A_{i t}^{2}\right)^{1 / 2}\left(T^{-2} \sum_{t=2}^{T} B_{i t}^{2}\right)^{1 / 2} \\
& =O_{p}\left(C_{N T}^{-1}\right) O_{p}\left(T^{-1 / 2}\right)
\end{aligned}
$$


For part $V$, if we let $B_{N T}=\min \left\{\sqrt{N T}, T^{3 / 4}\right\}$, then we have

$$
\begin{aligned}
V & =2 \lambda_{i}^{\prime} H^{-1} T^{-2} \sum_{t=2}^{T} e_{i t} V_{t}-2 d_{i}^{\prime} T^{-2} \sum_{t=2}^{T} e_{i t} \widehat{F}_{t} \\
& =2 \lambda_{i}^{\prime} H^{-1} T^{-2} \sum_{t=2}^{T} e_{i t} V_{t}-2 d_{i}^{\prime} T^{-2} \sum_{t=2}^{T} e_{i t}\left(\widehat{F}_{t}-H F_{t}\right) \\
& +2 d_{i}^{\prime} H T^{-1}\left(T^{-1} \sum_{t=2}^{T} e_{i t} F_{t}\right) \\
& =O_{p}\left(T^{-1 / 2}\right)+O_{p}\left(D_{N T}^{-1}\right) O_{p}\left(B_{N T}^{-1}\right)+O_{p}\left(D_{N T}^{-1}\right) T^{-1} O_{p}(1),
\end{aligned}
$$

where the order of the last term follows from the fact that $F_{t}$ is stationary and independent of $e_{i t}$. The evaluation of the second term on the right-hand side involves some very tedious, although relatively straightforward, algebra and is therefore omitted. But it can be shown that

$$
T^{-2} \sum_{t=2}^{T} e_{i t}\left(\widehat{F}_{t}-H F_{t}\right)=O_{p}\left(B_{N T}^{-1}\right),
$$

which implies

$$
\begin{aligned}
T^{-2} \sum_{t=2}^{T} e_{i t} V_{t} & =T^{-2} \sum_{t=2}^{T} e_{i t}\left(\widehat{F}_{t}-H F_{t}\right)+H F_{1} T^{-1 / 2}\left(T^{-3 / 2} \sum_{t=2}^{T} e_{i t}\right) \\
& =O_{p}\left(B_{N T}^{-1}\right)+T^{-1 / 2} O_{p}(1),
\end{aligned}
$$

where we have used that $V_{t}=\widehat{F}_{t}-H F_{t}+H F_{1}$ and $F_{1}=O_{p}(1)$.

Finally, consider part $V I I$. The first two terms within the parenthesis are $O_{p}\left(T^{-1 / 2}\right)$ and $O_{p}\left(T^{-1}\right)$, respectively. For the last term, we have

$$
\begin{aligned}
T^{-2} \sum_{t=2}^{T} A_{i t} & =\lambda_{i}^{\prime} H^{-1} T^{-2} \sum_{t=2}^{T} V_{t}-d_{i}^{\prime} T^{-2} \sum_{t=2}^{T} \widehat{F}_{t} \\
& =\lambda_{i}^{\prime} H^{-1} T^{-2} \sum_{t=2}^{T} V_{t}-d_{i}^{\prime} T^{-2} \sum_{t=2}^{T}\left(\widehat{F}_{t}-H F_{t}\right) \\
& +d_{i}^{\prime} H T^{-1}\left(T^{-1} \sum_{t=2}^{T} F_{t}\right) \\
& =O_{p}\left(N^{-1}\right)+O_{p}\left(D_{N T}^{-1}\right) O_{p}\left(N^{-1}\right)+O_{p}\left(D_{N T}^{-1}\right) T^{-1} O_{p}(1),
\end{aligned}
$$

where $\left\|V_{t}\right\|=O_{p}(T / N)$ as shown by Bai and $\mathrm{Ng}$ (2004). Thus, by collecting all the terms, we can show that (A9) reduces to

$$
T^{-2} \sum_{t=2}^{T} \widehat{e}_{i t}^{2}=T^{-2} \sum_{t=2}^{T} e_{i t}^{2}+O_{p}\left(D_{N T}^{-1}\right) .
$$

This establishes (e) and thus the proof of Lemma A.3 is complete. 


\section{Proof of Theorem 1}

Consider first the $D H_{g}$ statistic. Under the null hypothesis that $\phi_{i}=1$ for all $i, \widehat{\phi}_{i}$ may be written as

$$
\begin{aligned}
T \widehat{\phi}_{i} & =T\left(\sum_{t=2}^{T} \widehat{e}_{i t-1}^{2}\right)^{-1} \sum_{t=2}^{T} \widehat{e}_{i t-1} \widehat{e}_{i t} \\
& =T+\left(T^{-2} \sum_{t=2}^{T} \widehat{e}_{i t-1}^{2}\right)^{-1} T^{-1} \sum_{t=2}^{T} \widehat{e}_{i t-1} \Delta \widehat{e}_{i t} .
\end{aligned}
$$

Similarly, for the IV estimator, we have

$$
\begin{aligned}
T \widetilde{\phi}_{i} & =T\left(\sum_{t=2}^{T} \widehat{e}_{i t-1} \widehat{e}_{i t}\right)^{-1} \sum_{t=2}^{T} \widehat{e}_{i t}^{2} \\
& =T+\left(T^{-2} \sum_{t=2}^{T} \widehat{e}_{i t-1} \widehat{e}_{i t}\right)^{-1} T^{-1} \sum_{t=2}^{T} \widehat{e}_{i t} \Delta \widehat{e}_{i t} .
\end{aligned}
$$

Now, making use of Lemma A.3, it is possible to show that the following results hold as $N, T \rightarrow \infty$

$$
\begin{aligned}
T^{-2} \sum_{t=2}^{T} \widehat{e}_{i t}^{2} & =T^{-2} \sum_{t=2}^{T} e_{i t}^{2}+O_{p}\left(D_{N T}^{-1}\right) \Rightarrow \omega_{i}^{2} \int_{0}^{1} W_{i}(r)^{2} \mathrm{~d} r \\
T^{-2} \sum_{t=2}^{T} \widehat{e}_{i t-1}^{2} & =T^{-2} \sum_{t=2}^{T} e_{i t-1}^{2}+O_{p}\left(D_{N T}^{-1}\right) \Rightarrow \omega_{i}^{2} \int_{0}^{1} W_{i}(r)^{2} \mathrm{~d} r \\
T^{-1} \sum_{t=2}^{T} \widehat{e}_{i t-1} \Delta \widehat{e}_{i t} & =T^{-1} \sum_{t=2}^{T} e_{i t-1} \Delta e_{i t}+O_{p}\left(C_{N T}^{-2}\right) \\
& \Rightarrow \omega_{i}^{2} \int_{0}^{1} W_{i}(r) \mathrm{d} W_{i}(r)+\gamma_{i}, \\
T^{-1} \sum_{t=2}^{T}\left(\Delta \widehat{e}_{i t}\right)^{2} & =T^{-1} \sum_{t=2}^{T}\left(\Delta e_{i t}\right)^{2}+O_{p}\left(C_{N T}^{-2}\right) \rightarrow_{p} \sigma_{i}^{2}
\end{aligned}
$$

where $\gamma_{i}=\left(\omega_{i}^{2}-\sigma_{i}^{2}\right) / 2$ is the onesided long-run variance of $z_{i t}$. By using that $\widehat{e}_{i t}=\widehat{e}_{i t-1}+\Delta \widehat{e}_{i t},(\mathrm{~A} 12)$ through (A15) imply that as $N, T \rightarrow \infty$

$$
\begin{aligned}
T^{-2} \sum_{t=2}^{T} \widehat{e}_{i t-1} \widehat{e}_{i t} & =T^{-2} \sum_{t=2}^{T} \widehat{e}_{i t}^{2}+T^{-1}\left(T^{-1} \sum_{t=2}^{T} \widehat{e}_{i t-1} \Delta \widehat{e}_{i t}\right) \\
& =T^{-2} \sum_{t=2}^{T} e_{i t}^{2}+O_{p}\left(D_{N T}^{-1}\right)+T^{-1} O_{p}\left(C_{N T}^{-2}\right) \\
& \Rightarrow \omega_{i}^{2} \int_{0}^{1} W_{i}(r)^{2} \mathrm{~d} r .
\end{aligned}
$$


By similar arguments, we get

$$
\begin{aligned}
T^{-1} \sum_{t=2}^{T} \widehat{e}_{i t} \Delta \widehat{e}_{i t} & =T^{-1} \sum_{t=2}^{T} \widehat{e}_{i t-1} \Delta \widehat{e}_{i t}+T^{-1} \sum_{t=2}^{T}\left(\Delta \widehat{e}_{i t}\right)^{2} \\
& =T^{-1} \sum_{t=2}^{T} e_{i t-1} \Delta e_{i t}+T^{-1} \sum_{t=2}^{T}\left(\Delta e_{i t}\right)^{2}+O_{p}\left(C_{N T}^{-2}\right) \\
& \Rightarrow \omega_{i}^{2} \int_{0}^{1} W_{i}(r) \mathrm{d} W_{i}(r)+\sigma_{i}^{2}+\gamma_{i}
\end{aligned}
$$

By combining (A10) through (A17), some algebra, and then discarding all rest terms of higher order than $O_{p}\left(D_{N T}^{-1}\right)$, we get

$$
\begin{aligned}
T\left(\widetilde{\phi}_{i}-\widehat{\phi}_{i}\right)= & \left(T^{-2} \sum_{t=2}^{T} \widehat{e}_{i t-1} \widehat{e}_{i t}\right)^{-1} T^{-1} \sum_{t=2}^{T} \widehat{e}_{i t} \Delta \widehat{e}_{i t}-\left(T^{-2} \sum_{t=2}^{T} \widehat{e}_{i t-1}^{2}\right)^{-1} \\
& T^{-1} \sum_{t=2}^{T} \widehat{e}_{i t-1} \Delta \widehat{e}_{i t} \\
= & \left(T^{-2} \sum_{t=2}^{T} e_{i t-1}^{2}\right)^{-1} T^{-1} \sum_{t=2}^{T}\left(\Delta e_{i t}\right)^{2}+O_{p}\left(D_{N T}^{-1}\right) \\
& \Rightarrow \sigma_{i}^{2}\left(\omega_{i}^{2} \int_{0}^{1} W_{i}(r)^{2} \mathrm{~d} r\right)^{-1} .
\end{aligned}
$$

Next, we prove the consistency of $\widehat{\sigma}_{i}^{2}$ and $\widehat{\omega}_{i}^{2}$. Consider $\widehat{\sigma}_{i}^{2}$, which can be written as $\widehat{\sigma}_{i}^{2}=T^{-1} \sum_{t=1}^{T} \widehat{v}_{i t}^{2}$, where $\widehat{v}_{i t}=\widehat{e}_{i t}-\widehat{\phi}_{i} \widehat{e}_{i t-1}=\Delta \widehat{e}_{i t}-\left(\widehat{\phi}_{i}-1\right) \widehat{e}_{i t-1}$. It follows that

$$
\begin{aligned}
\widehat{\sigma}_{i}^{2} & =T^{-1} \sum_{t=2}^{T}\left(\Delta \widehat{e}_{i t}-\left(\widehat{\phi}_{i}-1\right) \widehat{e}_{i t-1}\right)^{2} \\
& =T^{-1} \sum_{t=2}^{T}\left(\Delta \widehat{e}_{i t}\right)^{2}-2\left(\widehat{\phi}_{i}-1\right)\left(T^{-1} \sum_{t=2}^{T} \widehat{e}_{i t-1} \Delta \widehat{e}_{i t}\right) \\
& +T\left(\widehat{\phi}_{i}-1\right)^{2}\left(T^{-2} \sum_{t=2}^{T} \widehat{e}_{i t}^{2}\right) \\
& =T^{-1} \sum_{t=2}^{T}\left(\Delta \widehat{e}_{i t}\right)^{2}+O_{p}\left(T^{-1}\right) O_{p}(1)+T O_{p}\left(T^{-2}\right) O_{p}(1) \\
& =T^{-1} \sum_{t=2}^{T}\left(\Delta e_{i t}\right)^{2}+O_{p}\left(C_{N T}^{-2}\right) \\
\rightarrow p & \sigma_{i}^{2},
\end{aligned}
$$

where the third equality follows by using (A12) and (A14), and the fact that $\left(\widehat{\phi}_{i}-1\right)=O_{p}\left(T^{-1}\right)$ under the null. The fourth equality is a direct consequence 
of Lemma A.3 (c). Thus, $\widehat{\sigma}_{i}^{2}$ is consistent. Moreover, suppose that $T, M_{i} \rightarrow \infty$ with $M_{i} / T \rightarrow 0$, then the consistency of $\widehat{\omega}_{i}^{2}$ is an immediate consequence of the fact that $\widehat{e}_{i t}$ is consistent for $e_{i t}$ as shown in Lemma A.3 (b).

Equations (A13) and (A18), together with the consistency of $\widehat{\sigma}_{i}^{2}$ and $\widehat{\omega}_{i}^{2}$, suggest that the following result holds as $N, T \rightarrow \infty$

$$
\begin{aligned}
\widehat{E}_{i} & =\widehat{S}_{i}\left(\widetilde{\phi}_{i}-\widehat{\phi}_{i}\right)^{2} \sum_{t=2}^{T} \widehat{e}_{i t-1}^{2} \\
& =\widehat{S}_{i}\left(T\left(\widetilde{\phi}_{i}-\widehat{\phi}_{i}\right)\right)^{2}\left(T^{-2} \sum_{t=2}^{T} \widehat{e}_{i t-1}^{2}\right) \\
& =S_{i}\left(T^{-2} \sum_{t=2}^{T} e_{i t-1}^{2}\right)^{-1}\left(T^{-1} \sum_{t=2}^{T}\left(\Delta e_{i t}\right)^{2}\right)^{2}+O_{p}\left(D_{N T}^{-1}\right) \\
& =\omega_{i}^{2}\left(T^{-2} \sum_{t=2}^{T} e_{i t-1}^{2}\right)^{-1}+O_{p}\left(D_{N T}^{-1}\right) .
\end{aligned}
$$

This expression can be written as

$$
\widehat{E}_{i}=E_{i}+O_{p}\left(D_{N T}^{-1}\right),
$$

where $E_{i}$ is implicitly defined as the first term on the right-hand side of (A20). By using (A13) it is clear that $E_{i}$ converges weakly to $B_{i}$ as $N, T \rightarrow \infty$. Hence, by using Theorem 1 of Phillips and Moon (1999), we can now show that

$$
\begin{aligned}
N^{-1} D H_{g} & =\frac{1}{N} \sum_{i=1}^{N} \widehat{E}_{i}=\frac{1}{N} \sum_{i=1}^{N}\left(E_{i}+O_{p}\left(D_{N T}^{-1}\right)\right) \\
& =\frac{1}{N} \sum_{i=1}^{N} E_{i}+O_{p}\left(D_{N T}^{-1}\right) \rightarrow_{p} E\left(B_{i}\right) .
\end{aligned}
$$

The joint limit distribution of $D H_{g}$ can be obtained by writing

$$
\begin{aligned}
N^{-1 / 2} D H_{g}-\sqrt{N} E\left(B_{i}\right) & =\sqrt{N}\left(\frac{1}{N} \sum_{i=1}^{N} \widehat{E}_{i}-E\left(B_{i}\right)\right) \\
& =\sqrt{N}\left(\frac{1}{N} \sum_{i=1}^{N} E_{i}+O_{p}\left(D_{N T}^{-1}\right)-E\left(B_{i}\right)\right) \\
& =\sqrt{N}\left(\frac{1}{N} \sum_{i=1}^{N} E_{i}-E\left(B_{i}\right)\right)+\sqrt{N} O_{p}\left(D_{N T}^{-1}\right),
\end{aligned}
$$

where the last term on the right-hand side is

$$
\sqrt{N} O_{p}\left(D_{N T}^{-1}\right)=O_{p}\left(\sqrt{N} T^{-1 / 2}\right)+O_{p}\left(N^{-1 / 2}\right),
$$


which vanishes under the condition that $N / T \rightarrow 0$ as $N, T \rightarrow \infty$. Moreover, by using Theorem 3 of Phillips and Moon (1999), since $E_{i}$ is independent across $i$, the first term on the right-hand side converges to a standard normal variate. From these results it follows that

$$
N^{-1 / 2} D H_{g}-\sqrt{N} E\left(B_{i}\right) \Rightarrow N\left(0, \operatorname{var}\left(B_{i}\right)\right) .
$$

This establishes the first part of the proof.

Consider next the limiting distribution of the $D H_{p}$ statistic. The expression for $\widehat{\phi}$ is given by

$$
\widehat{\phi}=\left(\sum_{i=1}^{N} \sum_{t=2}^{T} \widehat{e}_{i t-1}^{2}\right)^{-1} \sum_{i=1}^{N} \sum_{t=2}^{T} \widehat{e}_{i t-1} \widehat{e}_{i t} .
$$

Similarly, $\widetilde{\phi}$ can be written as

$$
\widetilde{\phi}=\left(\sum_{i=1}^{N} \sum_{t=2}^{T} \widehat{e}_{i t-1} \widehat{e}_{i t}\right)^{-1} \sum_{i=1}^{N} \sum_{t=2}^{T} \widehat{e}_{i t}^{2} .
$$

As in (A18), $\widetilde{\phi}$ and $\widehat{\phi}$ can be combined to obtain

$$
\begin{aligned}
T(\widetilde{\phi}-\widehat{\phi}) & =\left(T^{-2} \sum_{i=1}^{N} \sum_{t=2}^{T} \widehat{e}_{i t-1} \widehat{e}_{i t}\right)^{-1} T^{-1} \sum_{i=1}^{N} \sum_{t=2}^{T} \widehat{e}_{i t} \Delta \widehat{e}_{i t} \\
& -\left(T^{-2} \sum_{i=1}^{N} \sum_{t=2}^{T} \widehat{e}_{i t-1}^{2}\right)^{-1} T^{-1} \sum_{i=1}^{N} \sum_{t=2}^{T} \widehat{e}_{i t-1} \Delta \widehat{e}_{i t} \\
& =\left(\frac{1}{N T^{2}} \sum_{i=1}^{N} \sum_{t=2}^{T} e_{i t-1}^{2}\right)^{-1} \frac{1}{N T} \sum_{i=1}^{N} \sum_{t=2}^{T}\left(\Delta e_{i t}\right)^{2}+O_{p}\left(D_{N T}^{-1}\right)
\end{aligned}
$$

Let $\sigma_{N}^{2}$ denote the cross-sectional average of $\sigma_{i}^{2}$. Given that the limit $\sigma_{N}^{2} \rightarrow$ $\sigma^{2}<\infty$ as $N \rightarrow \infty$ exist, since $\widehat{\sigma}_{i}^{2}$ is consistent for $\sigma_{i}^{2}$ as $N, T \rightarrow \infty$, we have

$$
\frac{1}{N T} \sum_{i=1}^{N} \sum_{t=2}^{T}\left(\Delta e_{i t}\right)^{2} \rightarrow{ }_{p} \sigma^{2}
$$

Moreover, by (A13) and Corollary 1 of Phillips and Moon (1999), we obtain

$$
\frac{1}{N T^{2}} \sum_{i=1}^{N} \sum_{t=2}^{T} e_{i t-1}^{2} \rightarrow_{p} \omega^{2} E\left(C_{i}\right),
$$

where $\omega_{N}^{2}$, the average $\omega_{i}^{2}$ across $i$, is assumed to satisfy $\omega_{N}^{2} \rightarrow \omega^{2}<\infty$ while passing $N \rightarrow \infty$. 
Now, similar to (A20), it is possible to show that

$$
\begin{aligned}
D H_{p} & =\widehat{S}_{N}(\widetilde{\phi}-\widehat{\phi})^{2}\left(\sum_{i=1}^{N} \sum_{t=2}^{T} \widehat{e}_{i t-1}^{2}\right)^{-1} \\
& =\widehat{S}_{N}(T(\widetilde{\phi}-\widehat{\phi}))^{2}\left(T^{-2} \sum_{i=1}^{N} \sum_{t=2}^{T} \widehat{e}_{i t-1}^{2}\right)^{-1} \\
& =S_{N}\left(T^{-2} \sum_{i=1}^{N} \sum_{t=2}^{T} e_{i t-1}^{2}\right)^{-1}\left(T^{-1} \sum_{i=1}^{N} \sum_{t=2}^{T}\left(\Delta e_{i t}\right)^{2}\right)^{2}+O_{p}\left(D_{N T}^{-1}\right)
\end{aligned}
$$

Thus, making use of the above convergence results, it follows that

$$
\begin{aligned}
N^{-1} D H_{p} & =S_{N}\left(\frac{1}{N T^{2}} \sum_{i=1}^{N} \sum_{t=2}^{T} e_{i t-1}^{2}\right)^{-1}\left(\frac{1}{N T} \sum_{i=1}^{N} \sum_{t=2}^{T}\left(\Delta e_{i t}\right)^{2}\right)^{2} \\
& +O_{p}\left(D_{N T}^{-1}\right) \\
& =\omega_{N}^{2}\left(\frac{1}{N T^{2}} \sum_{i=1}^{N} \sum_{t=2}^{T} e_{i t-1}^{2}\right)^{-1}+O_{p}\left(D_{N T}^{-1}\right) \\
& \rightarrow p \omega^{2}\left(\omega^{2} E\left(C_{i}\right)\right)^{-1}
\end{aligned}
$$

Therefore, $N^{-1} D H_{p}$ converges in probability to $E\left(C_{i}\right)^{-1}$ as $N, T \rightarrow \infty$. To obtain the joint limit of $D H_{p}$, write

$$
\begin{aligned}
N^{-1 / 2} D H_{p}-\sqrt{N} E\left(C_{i}\right)^{-1} & =\sqrt{N}\left(N^{-1} D H_{p}-E\left(C_{i}\right)^{-1}\right) \\
& =\sqrt{N}\left(E_{N}+O_{p}\left(D_{N T}^{-1}\right)-E\left(C_{i}\right)^{-1}\right) \\
& =\sqrt{N}\left(E_{N}-E\left(C_{i}\right)^{-1}\right)+\sqrt{N} O_{p}\left(D_{N T}^{-1}\right),
\end{aligned}
$$

where $E_{N}$ is implicitly defined in (A21) as

$$
E_{N}=\omega_{N}^{2}\left(\frac{1}{N T^{2}} \sum_{i=1}^{N} \sum_{t=2}^{T} e_{i t-1}^{2}\right)^{-1} .
$$

Note that the second term vanishes under the condition that $N / T \rightarrow \infty$ as $N, T \rightarrow \infty$. Therefore, by using the Delta method and the independence of $e_{i t}$ across $i$, we get

$$
\sqrt{N}\left(N^{-1} D H_{p}-E\left(C_{i}\right)^{-1}\right) \Rightarrow N\left(0, E\left(C_{i}\right)^{-4} \operatorname{var}\left(C_{i}\right)\right) .
$$

This establishes the second part of the proof. 
Table 1: Size and power at the $5 \%$ level for the tests with a nonstationary regressor and estimated slope.

\begin{tabular}{|c|c|c|c|c|c|c|c|c|c|c|}
\hline$\phi$ & Case & $T$ & $N$ & $D H_{g}$ & $\widetilde{Z}_{t}$ & $\widetilde{Z}_{\rho}$ & $D H_{p}$ & $Z_{t}$ & $Z_{\rho}$ & $Z_{v}$ \\
\hline \multirow[t]{12}{*}{1} & \multirow[t]{4}{*}{1} & \multirow[t]{2}{*}{100} & 10 & 11.3 & 10.4 & 7.8 & 12.2 & 7.4 & 8.0 & 9.0 \\
\hline & & & 20 & 12.6 & 13.8 & 8.4 & 10.1 & 7.8 & 5.5 & 5.9 \\
\hline & & \multirow[t]{2}{*}{200} & 10 & 11.1 & 8.5 & 8.6 & 11.4 & 6.6 & 8.2 & 9.5 \\
\hline & & & 20 & 8.6 & 10.5 & 8.8 & 7.7 & 6.8 & 7.0 & 6.3 \\
\hline & \multirow[t]{4}{*}{2} & \multirow[t]{2}{*}{100} & 10 & 12.0 & 82.0 & 84.6 & 10.5 & 80.5 & 88.0 & 75.1 \\
\hline & & & 20 & 12.1 & 95.5 & 96.7 & 7.8 & 92.9 & 97.6 & 90.3 \\
\hline & & \multirow[t]{2}{*}{200} & 10 & 8.7 & 74.3 & 80.3 & 12.3 & 79.3 & 89.2 & 70.7 \\
\hline & & & 20 & 8.7 & 92.9 & 94.9 & 8.8 & 93.4 & 98.7 & 87.9 \\
\hline & \multirow[t]{4}{*}{3} & \multirow[t]{2}{*}{100} & 10 & 10.4 & 96.3 & 96.6 & 9.4 & 70.9 & 98.9 & 94.0 \\
\hline & & & 20 & 10.9 & 99.8 & 99.9 & 7.2 & 76.9 & 100.0 & 99.5 \\
\hline & & \multirow[t]{2}{*}{200} & 10 & 9.5 & 93.7 & 95.1 & 11.1 & 68.4 & 98.9 & 92.1 \\
\hline & & & 20 & 10.8 & 99.6 & 99.9 & 8.3 & 79.1 & 100.0 & 99.4 \\
\hline \multirow[t]{12}{*}{0.98} & \multirow[t]{4}{*}{1} & \multirow[t]{2}{*}{100} & 10 & 39.4 & 14.7 & 19.6 & 73.4 & 13.9 & 21.0 & 51.1 \\
\hline & & & 20 & 68.1 & 21.7 & 31.4 & 97.9 & 22.9 & 37.0 & 83.6 \\
\hline & & \multirow[t]{2}{*}{200} & 10 & 84.7 & 27.9 & 38.0 & 99.6 & 30.1 & 50.7 & 90.1 \\
\hline & & & 20 & 99.3 & 52.0 & 69.6 & 100.0 & 56.6 & 80.7 & 99.9 \\
\hline & \multirow[t]{4}{*}{2} & \multirow[t]{2}{*}{100} & 10 & 39.6 & 18.1 & 17.2 & 78.2 & 15.3 & 24.4 & 31.4 \\
\hline & & & 20 & 64.2 & 20.3 & 19.7 & 98.8 & 23.2 & 31.9 & 49.7 \\
\hline & & \multirow[t]{2}{*}{200} & 10 & 91.2 & 38.0 & 29.4 & 99.7 & 28.7 & 45.3 & 66.4 \\
\hline & & & 20 & 99.9 & 53.3 & 46.1 & 100.0 & 41.4 & 73.1 & 91.3 \\
\hline & \multirow[t]{4}{*}{3} & \multirow[t]{2}{*}{100} & 10 & 34.3 & 12.0 & 11.4 & 74.8 & 13.5 & 15.1 & 23.4 \\
\hline & & & 20 & 69.5 & 21.3 & 20.5 & 96.3 & 27.2 & 34.0 & 41.1 \\
\hline & & \multirow[t]{2}{*}{200} & 10 & 88.2 & 37.8 & 34.6 & 99.5 & 32.4 & 43.7 & 57.5 \\
\hline & & & 20 & 99.4 & 49.6 & 44.8 & 100.0 & 62.0 & 71.4 & 86.5 \\
\hline \multirow[t]{12}{*}{0.95} & \multirow[t]{4}{*}{1} & \multirow[t]{2}{*}{100} & 10 & 95.0 & 50.2 & 63.7 & 100.0 & 48.9 & 71.0 & 97.8 \\
\hline & & & 20 & 100.0 & 74.5 & 88.1 & 100.0 & 80.2 & 96.4 & 100.0 \\
\hline & & \multirow[t]{2}{*}{200} & 10 & 100.0 & 97.9 & 98.8 & 100.0 & 99.0 & 99.9 & 100.0 \\
\hline & & & 20 & 100.0 & 100.0 & 100.0 & 100.0 & 100.0 & 100.0 & 100.0 \\
\hline & \multirow[t]{4}{*}{2} & 100 & 10 & 94.9 & 44.9 & 40.6 & 99.9 & 30.6 & 56.0 & 72.5 \\
\hline & & & 20 & 100.0 & 58.0 & 52.2 & 100.0 & 51.0 & 74.0 & 94.9 \\
\hline & & 200 & 10 & 100.0 & 89.8 & 79.3 & 100.0 & 68.9 & 92.1 & 99.8 \\
\hline & & & 20 & 100.0 & 99.0 & 96.6 & 100.0 & 86.6 & 100.0 & 100.0 \\
\hline & 3 & 100 & 10 & 90.1 & 35.1 & 33.8 & 99.4 & 37.2 & 46.3 & 63.3 \\
\hline & & & 20 & 100.0 & 55.5 & 52.5 & 99.9 & 67.5 & 75.5 & 88.3 \\
\hline & & 200 & 10 & 100.0 & 83.5 & 76.0 & 100.0 & 80.8 & 87.0 & 95.9 \\
\hline & & & 20 & 100.0 & 97.7 & 96.5 & 100.0 & 99.5 & 99.5 & 100.0 \\
\hline
\end{tabular}

Notes: The value $\phi$ refers to the autoregressive parameter in the idiosyncratic error term. In Case $1, \lambda_{i}=0$, in Case $2, \lambda_{i} \sim N(0,1)$ and in Case $3, \lambda_{i} \sim N(1,1)$, where $\lambda_{i}$ is the loading of the common factor. 
Table 2: Size at the $5 \%$ level for the tests with a stationary regressor and estimated slope.

\begin{tabular}{|c|c|c|c|c|c|c|c|c|c|c|}
\hline$\delta$ & Case & $T$ & $N$ & $D H_{g}$ & $\widetilde{Z}_{t}$ & $\widetilde{Z}_{\rho}$ & $D H_{p}$ & $Z_{t}$ & $Z_{\rho}$ & $Z_{v}$ \\
\hline \multirow[t]{12}{*}{0.9} & 1 & 100 & 10 & 10.6 & 3.5 & 1.3 & 10.9 & 3.4 & 2.4 & 0.9 \\
\hline & & & 20 & 14.4 & 2.4 & 0.9 & 7.4 & 3.0 & 1.5 & 0.0 \\
\hline & & 200 & 10 & 9.2 & 0.9 & 0.6 & 11.0 & 1.9 & 1.9 & 0.2 \\
\hline & & & 20 & 8.3 & 0.7 & 0.7 & 8.0 & 1.1 & 1.0 & 0.7 \\
\hline & 2 & 100 & 10 & 11.1 & 63.1 & 66.8 & 12.2 & 67.5 & 75.6 & 46.7 \\
\hline & & & 20 & 10.5 & 79.6 & 81.9 & 8.4 & 81.3 & 88.4 & 57.6 \\
\hline & & 200 & 10 & 9.1 & 46.5 & 55.3 & 11.6 & 64.2 & 74.3 & 31.9 \\
\hline & & & 20 & 8.5 & 62.4 & 71.9 & 8.8 & 81.9 & 89.7 & 42.8 \\
\hline & 3 & 100 & 10 & 13.1 & 90.1 & 92.0 & 12.5 & 50.3 & 96.4 & 80.1 \\
\hline & & & 20 & 14.9 & 98.1 & 98.9 & 9.2 & 53.4 & 99.4 & 94.1 \\
\hline & & 200 & 10 & 9.9 & 80.9 & 85.3 & 12.0 & 46.2 & 95.8 & 70.5 \\
\hline & & & 20 & 10.6 & 95.6 & 97.9 & 9.5 & 47.7 & 99.4 & 87.0 \\
\hline \multirow[t]{12}{*}{0.5} & 1 & 100 & 10 & 11.1 & 0.5 & 0.2 & 9.6 & 0.5 & 0.7 & 0.2 \\
\hline & & & 20 & 11.6 & 0.0 & 0.0 & 8.8 & 0.5 & 0.1 & 0.0 \\
\hline & & 200 & 10 & 9.9 & 0.3 & 0.1 & 13.9 & 0.5 & 0.6 & 0.8 \\
\hline & & & 20 & 9.8 & 0.0 & 0.0 & 7.5 & 0.2 & 0.2 & 0.2 \\
\hline & 2 & 100 & 10 & 10.9 & 40.4 & 47.2 & 11.8 & 57.5 & 62.1 & 36.2 \\
\hline & & & 20 & 12.2 & 56.0 & 63.9 & 8.6 & 71.6 & 80.2 & 44.1 \\
\hline & & 200 & 10 & 9.2 & 31.5 & 39.8 & 11.0 & 54.9 & 64.1 & 28.4 \\
\hline & & & 20 & 7.9 & 37.5 & 52.8 & 8.6 & 71.3 & 83.2 & 32.6 \\
\hline & 3 & 100 & 10 & 13.0 & 80.5 & 84.2 & 12.4 & 38.3 & 93.0 & 75.6 \\
\hline & & & 20 & 14.1 & 93.5 & 95.7 & 9.3 & 37.5 & 98.9 & 90.2 \\
\hline & & 200 & 10 & 8.9 & 72.1 & 79.2 & 10.0 & 41.3 & 94.7 & 69.3 \\
\hline & & & 20 & 9.8 & 85.3 & 92.4 & 9.5 & 35.6 & 99.7 & 82.0 \\
\hline
\end{tabular}

Notes: The value $\delta$ refers to the autoregressive parameter of the regressor. See Table 1 for an explanation of the remaining features of the table. 
Table 3: Size and power at the $5 \%$ level for the tests with a nonstationary regressor and predetermined slope.

\begin{tabular}{|c|c|c|c|c|c|c|c|c|}
\hline \multirow[b]{2}{*}{$b$} & \multirow[b]{2}{*}{$T$} & \multirow[b]{2}{*}{$N$} & \multicolumn{2}{|l|}{$\phi=1$} & \multicolumn{2}{|c|}{$\phi=0.98$} & \multicolumn{2}{|c|}{$\phi=0.95$} \\
\hline & & & $D H_{g}$ & $D H_{p}$ & $D H_{g}$ & $D H_{p}$ & $D H_{g}$ & $D H_{p}$ \\
\hline \multirow[t]{4}{*}{1} & 100 & 10 & 12.6 & 12.5 & 39.1 & 71.7 & 97.6 & 100.0 \\
\hline & & 20 & 9.7 & 9.1 & 74.5 & 98.3 & 100.0 & 100.0 \\
\hline & 200 & 10 & 11.5 & 11.1 & 91.5 & 99.6 & 100.0 & 100.0 \\
\hline & & 20 & 9.7 & 7.7 & 100.0 & 100.0 & 100.0 & 100.0 \\
\hline \multirow[t]{4}{*}{1.5} & 100 & 10 & 13.1 & 12.9 & 19.7 & 37.7 & 52.3 & 76.9 \\
\hline & & 20 & 12.8 & 8.6 & 40.2 & 80.5 & 85.2 & 99.0 \\
\hline & 200 & 10 & 8.2 & 11.6 & 49.5 & 78.0 & 85.7 & 94.1 \\
\hline & & 20 & 10.0 & 8.3 & 76.0 & 98.5 & 97.9 & 100.0 \\
\hline \multirow[t]{4}{*}{3} & 100 & 10 & 11.2 & 12.1 & 6.7 & 9.2 & 8.2 & 8.9 \\
\hline & & 20 & 12.8 & 9.8 & 9.1 & 10.1 & 11.1 & 13.8 \\
\hline & 200 & 10 & 7.5 & 10.9 & 10.5 & 9.1 & 12.5 & 10.2 \\
\hline & & 20 & 9.2 & 10.3 & 9.7 & 10.8 & 14.6 & 14.6 \\
\hline
\end{tabular}

Notes: The value $b$ refers to the predetermined slope. The true slope is equal to one. See Table 1 for an explanation of the remaining features of the table. 


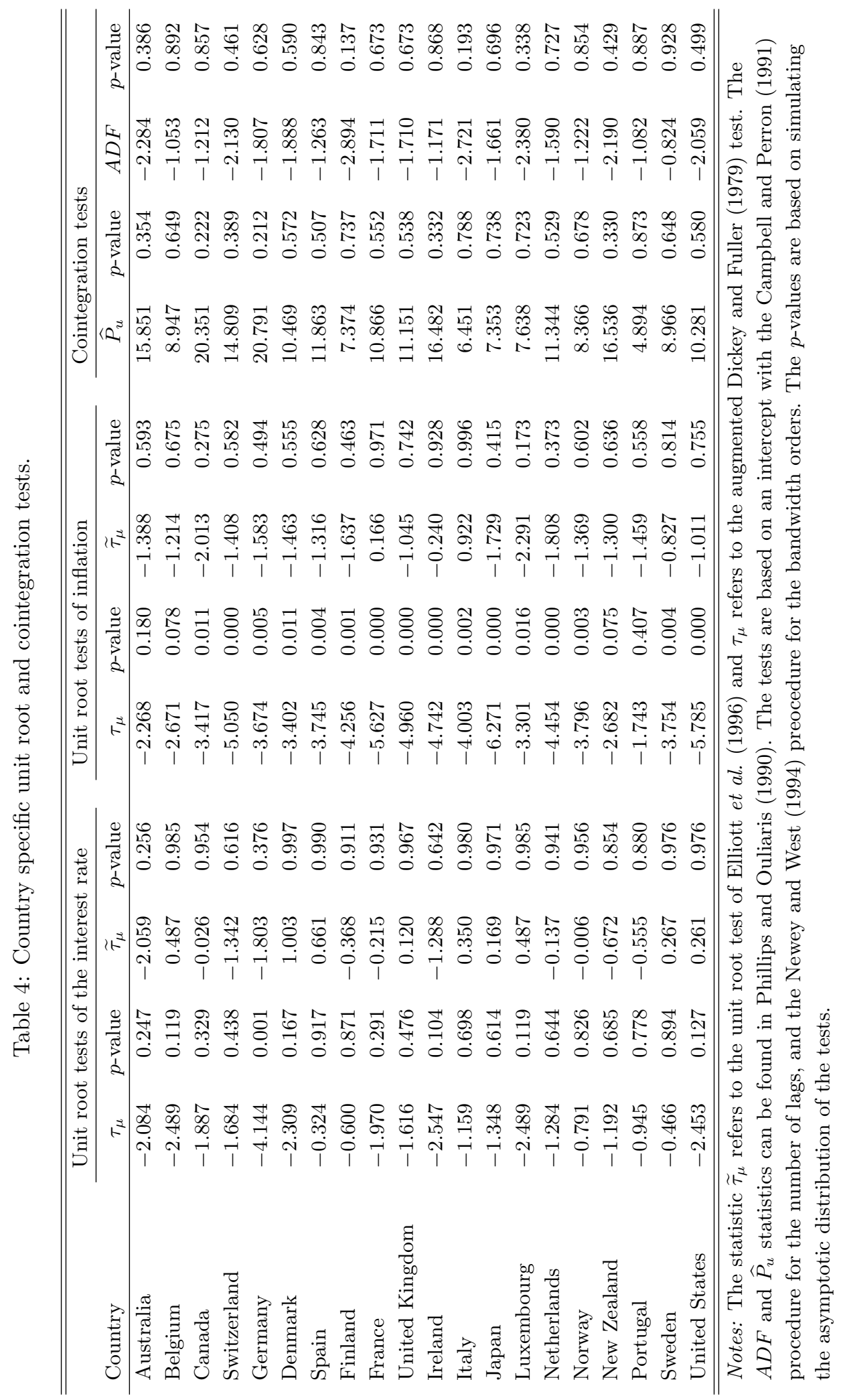


Table 5: Panel cointegration tests.

\begin{tabular}{|c|c|c|c|c|c|}
\hline \multirow[b]{2}{*}{ Study } & \multirow[b]{2}{*}{ Test } & \multicolumn{2}{|c|}{ Estimated $\beta_{i}$} & \multicolumn{2}{|c|}{ Predetermined $\beta_{i}^{\text {a }}$} \\
\hline & & Value & $p$-value & Value & $p$-value \\
\hline \multirow[t]{2}{*}{ This study } & $D H_{g}$ & 10.588 & 0.000 & 137.523 & 0.000 \\
\hline & $D H_{p}$ & 24.582 & 0.000 & 129.318 & 0.000 \\
\hline \multirow[t]{5}{*}{ Pedroni (2004) } & $\widetilde{Z}_{t}$ & -12.212 & 0.000 & - & - \\
\hline & $\widetilde{Z}_{\rho}$ & -16.944 & 0.000 & - & - \\
\hline & $Z_{t}$ & -8.167 & 0.000 & - & - \\
\hline & $Z_{\rho}$ & -21.333 & 0.000 & - & - \\
\hline & $Z_{v}$ & 1.523 & 0.064 & - & - \\
\hline
\end{tabular}

Notes: All tests are based on an intercept and the Newey and West (1994) procedure for selecting the bandwidth order. The $p$-values are based on the asymptotic normal distribution.

${ }^{\mathrm{a}}$ The predetermined $\beta_{i}$ is set equal to one.

Table 6: Panel unit root tests.

\begin{tabular}{lrrrrr}
\hline \hline & \multicolumn{2}{c}{ Inflation } & & \multicolumn{2}{c}{ Interest rate } \\
\cline { 2 - 3 } \cline { 5 - 6 } Test & Value & $p$-value & & Value & $p$-value \\
\hline $\bar{t}$ & -4.619 & 0.011 & & 1.872 & 1.000 \\
$\overline{L M}$ & 4.166 & 0.013 & & -2.990 & 1.000 \\
$\overline{\max }$ & 4.113 & 1.000 & & 1.534 & 1.000 \\
$\overline{\min }$ & -1.977 & 1.000 & & -2.549 & 1.000 \\
\hline \hline
\end{tabular}

Notes: All tests are based on an intercept and the Campbell and Perron (1991) lag selection procedure. The $p$-values are based on the Smith et al. (2004) boostrap scheme. 


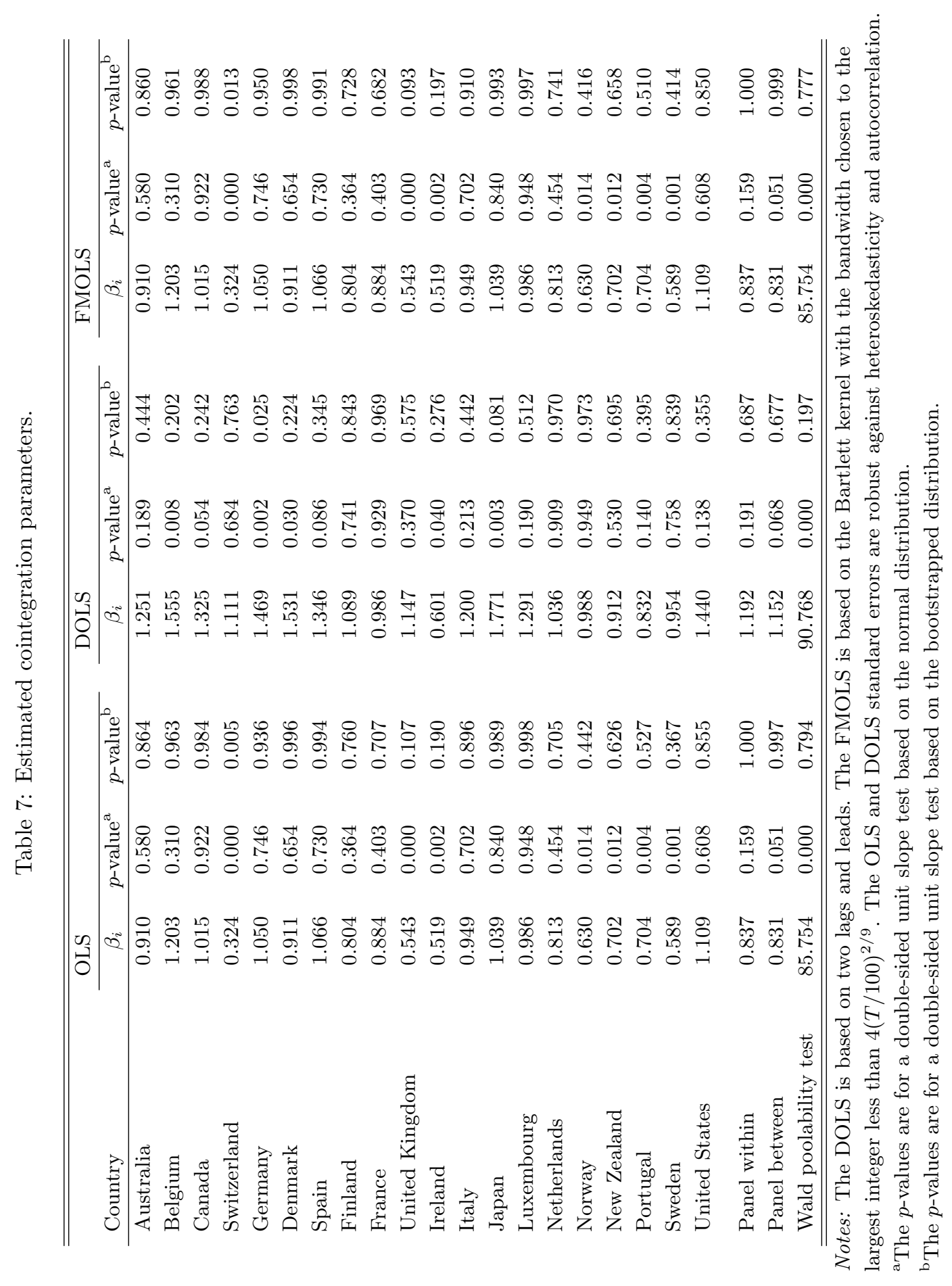




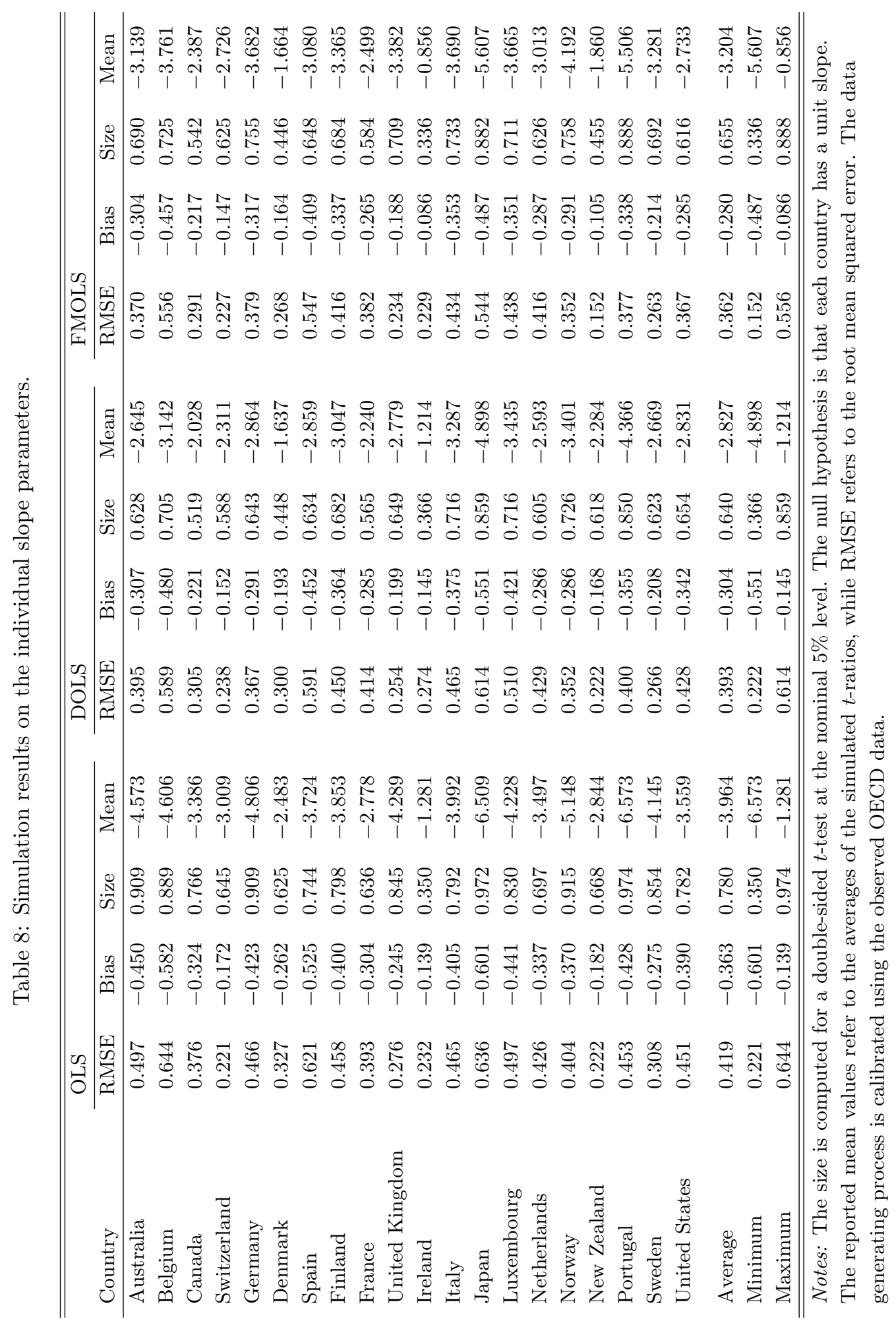




\section{References}

Atkins, F. J., and A. Serletis (2003). Bounds Tests of the Gibson Paradox and the Fisher Effect: Evidence from Low-Frequency International Data. The Manchester School, Vol. 71, pp. 673-679.

Bai, J., and S. Ng (2004). A Panic Attack on Unit Roots and Cointegration. Econometrica, Vol. 72, pp. 1127-1177.

Banerjee, A., and J. L. Carrion-i-Silvestre (2006). Cointegration in Panel Data with Breaks and Cross-Section Dependence. ECB working paper no. 591.

Berument, H., and M. M. Jelassi (2002). The Fisher Hypothesis: A MultiCountry Analysis. Applied Economics, Vol. 34, pp. 1645-1655.

Bonham, C. S. (1991). Correct Cointegration Tests of the Long-Run Relationship Between Nominal Interest and Inflation. Applied Economics, Vol. 23, pp. 1487-1492.

Campbell, J., and P. Perron (1991). Pitfalls and Opportunities: What Macroeconomists should Know about Unit Roots. In Blanchard, O., and S. Fishers (Eds.), NBER Macroeconomics Annual, MIT Press, Cambridge, MA.

Carmichael, J., and P. W. Stebbing (1983). Fisher's Paradox and the Theory of Interest. American Economic Review, Vol. 73, pp. 619-630.

Caporale, G. M., and N. Pittis (2004). Estimator Choice and Fisher's Paradox: A Monte Carlo Study. Econometric Reviews, Vol. 23, pp. 25-52.

Chang, Y., J. Y. Park and K. Song (2006). Bootstrapping Cointegrating Regressions. Journal of Econometrics, forthcoming.

Choi, I. (1994). Durbin-Hausman Tests for Cointegration. Journal of Economic Dynamics and Control, Vol. 18, pp. 467-480.

Culver, S. E., and D. H. Papell (1996). Is there a Unit Root in the Inflation Rate? Evidence From Sequential Break and Pane Data Models. Journal of Applied Econometrics, Vol. 12, pp. 435-444.

Crowder, W. J., and D. L. Hoffman (1996). The Long-Run Relationship Berween Nominal Interest Rates and Inflation: The Fisher Equation Revisited. Journal of Money, Credit and Banking, Vol. 28, pp. 102-118.

Darby, M. R. (1975). The Financial and Tax Effects of Monetary Policy on Interest Rates. Economic Inquiry, Vol. 13, pp. 266-256.

Dickey, D. A., and W. A. Fuller (1979). Distribution of the Estimator for Autoregressive Time Series with a Unit Root. Journal of the American Statistical Association, Vol. 74, pp. 427-431. 
Engsted, T. (1995). Does the Long-Term Interest Rate Predict Future Inflation? A Multi-Country Analysis. The Review of Economics and Statistics, Vol. 77 , pp. $42-54$.

Elliott, G., T. J. Rothenberg and J. H. Stock (1996). Efficient Test for an Autoregressive Unit Root. Econometrica, Vol. 64, pp. 813-836.

Evans, M. D. D., and K. K. Lewis (1995). Do Expected Shifts in Inflation Affect Estimates of the Long-Run Fisher Relation? Journal of Finance, Vol. 50, pp. 225-253.

Fisher, I. (1930). The Theory of Interest. MacMillan, New York.

Garratt, A., K. Lee, M. H. Pesaran and Y. Shin (2003). A Long-Run Structural Macroeconometric Model of the UK. The Economic Journal, Vol. 113, pp. 412-455.

Gengenbach, C., F. C. Palm and J-P. Urbain (2006). Cointegration Testing in Panels with Common Factors. Oxford Bulletin of Economics and Statistics, forthcoming.

Ghazali, N. A., and S. Ramlee (2003). A Long Memory Test of the Long-Run Fisher Effect in the G7 Countries. Applied Financial Economics, Vol. 13, pp. 763-769.

Lee, J. E. (2002). On the Characterisation of the World Real Interest Rate. The World Economy, Vol. 25, pp. 247-255.

Koustas, Z., and A. Serletis (1999). On the Fisher Effect. Journal of Monetary Economics, Vol. 44, pp. 105-130.

King, R. G., and M. W. Watson, 1997, Testing Long-Run Neutrality. Federal Reserve Bank of Richmond Economic Quarterly, Vol. 83, pp. 69-101.

MacDonald, R., and P. Murphy (1989). Testing for the Long-Run Relationships Between Nominal Interest Rates and Inflation Using Cointegration Techniques. Applied Economics, Vol. 21, pp. 439-447.

Mishkin, F. S. (1992). Is the Fisher effect for real? Journal of Monetary Economics, Vol. 30, pp. 195-215.

Mundell, R. (1963). Inflation and Real Interest. The Journal of Political Economy, Vol. 71, pp. 280-283.

Newey, W., and K. West (1994). Autocovariance Lag Selection in Covariance Matrix Estimation. Review of Economic Studies, Vol. 61, pp. 613-653.

Ng, S., and P. Perron (1997). Estimation and Inference in Nearly Unbalanced Nearly Cointegrated Systems. Journal of Econometrics, Vol. 73, pp. 5381. 
O'Connell, P. (1998). Overvaluation of Purchasing Power Parity. Journal of International Economics, Vol. 44, pp. 1-19.

Owen, P. D. (1993). Cointegration Analysis of the Fisher Hypothesis: The Role of the Real Rate and the Fisher Identity. Applied Financial Economics, Vol. 3, pp. 21-26.

Pedroni, P. (2000). Fully Modified OLS for Heterogeneous Cointegrated Panels. In Baltagi, B. H. (Ed.), Nonstationary Panels, Panel Cointegration, and Dynamic Panels, Advances in Econometrics, Vol. 15, JAI Press, pp. 93-130.

Pedroni, P. (2001). Purchasing Power Parity in Cointegrated Panels. The Review of Economics and Statistics, Vol. 83, pp. 727-731.

Pedroni, P. (2004). Panel Cointegration: Asymptotic and Finite Sample Properties of Pooled Time Series Tests with an Application to the PPP Hypothesis. Econometric Theory, Vol. 3, pp. 579-625.

Pesaran, M. H., Y. Shin and R. J. Smith (2001). Bounds Testing Approaches to the Analysis of Level Relationships. Journal of Applied Econometrics, Vol. 16, pp. 289-326.

Phillips, P. C. B., and S. Ouliaris (1990). Asymptotic Properties of Residual Based Tests for Cointegration. Econometrica, Vol. 58, pp. 165-193.

Phillips, P. C. B., and H. R. Moon (1999). Linear Regression Limit Theory of Nonstationary Panel Data. Econometrica, Vol. 67, pp. 1057-1111.

Phillips, P. C. B., and B. E. Hansen (1990). Statistical Inference in Instrumental Variables Regression with I(1) Process. Review of Economics Studies, Vol. 57, pp. 99-125.

Rose, A. K. (1988). Is the Real Interest Rate Stable? Journal of Finance, Vol. 43, pp. 1095-1112.

Saikkonen, P. (1991). Asymptotic Efficient Estimation of Cointegration Regressions. Econometric Theory, Vol. 7, pp. 1-21.

Smith, V. L., S. Leybourne, T-H. Kim and P. Newbold (2004). More Powerful Panel Unit Root Tests with an Application to the Mean Reversion in Real Exchange Rates. Journal of Applied Econometrics, Vol. 19, pp. 147-170.

Strauss, J., and D. Terrell (1995). Cointegration Tests of the Fisher Hypothesis with Variable Trends in the World Real Interest Rate. Southern Economic Journal, Vol. 61, pp. 1047-1056.

Tobin, J. (1965). Money and Economic Growth. Econometrica, Vol. 33, pp. 671-684. 
Valkanov, R. (2003). Long-Horizon Regressions: Theoretical Results and Applications. Journal of Financial Economics, Vol. 68, pp. 201-232.

Westerlund, J. (2005). New Simple Tests for Panel Cointegration. Econometrics Reviews, Vol. 24, pp. 297-316.

Westerlund, J., and D. L. Edgerton (2006). New Improved Tests for Cointegration with Structural Breaks. Journal of Time Series Analysis, forthcoming. 